\title{
An Overview of Maritime Waterway Quantitative Risk
}

\author{
Assessment Models \\ Suyi Li, Qiang Meng, and Xiaobo Qu \\ National University of Singapore \\ Published in
}

Risk Analysis, Vol. 32, No. 3, 2012

DOI: 10.1111j.1539-6924.2011.01697.x 


\begin{abstract}
The safe navigation of ships, especially in narrow shipping waterways, is of utmost concern to researchers as well as maritime authorities. Numerous researchers and practitioners conduct many studies on the risk assessment for the maritime transportation and propose risk reduction/control measures accordingly. This paper provides a detailed review and assessment of various quantitative risk assessment (QRA) models for maritime waterways. Eighty seven academic papers and project reports are summarized and discussed in this paper. The paper then proceeds to analyze the frequency and consequence estimation models separately. It should be pointed out that we further summarize the advantages and disadvantages of the frequency estimation models and provide recommendations for their applications. From the overview, we find that quantification of impact of human errors is of great importance to the future studies. The possible solutions are also proposed in the conclusive section.
\end{abstract}

Key Words: Maritime waterway; quantitative risk assessment; ship collision and grounding; causation probability 


\section{INTRODUCTION}

The safe navigation of ships, especially in narrow shipping waterways, is of utmost concern to the maritime authorities. Several ship collision accidents have aroused the awareness of researchers and maritime authorities. Quantitative risk assessment (QRA) model for shipping waterways, thus far, has enjoyed a growing interest in the past years. This paper conducts an overview of QRA models developed for maritime waterway, including straits, gulfs, and bays. According to International Maritime Organization (IMO) report ${ }^{(1,2)}$, several technical terms are defined as follows:

Risk: combination of frequency and severity of consequence.

Accident: an unintended event involving fatality, injury, ship loss or damage, other property loss or damage, or environmental damage.

Consequence: outcome of an accident.

Frequency: number of occurrences per unit time (e.g. per year).

Hazard: a potential to threaten human life, health, property or the environment.

Collision: striking or being struck by another ship, regardless of whether under way, anchored or moored. This category does not include striking underwater wrecks.

Contact: striking any fixed or floating objects other than those included under collision or grounding.

Grounding: being aground or hitting/touching shore or sea bottom or underwater objects (wrecks, etc.)

Fire: incidents where fire is the initial event.

Explosion: incidents where explosion is the initial event.

Non-accidental structural failure (NASF): scenarios when the hull presents cracks and fractures, affecting ship's seaworthiness. 
This literature review is conducted by searching various databases. With access to the digital library of National University of Singapore (NUS),, including hundreds of journals as well as conference proceedings, the search could cover most published research works worldwide. The databases provided by SCOPUS $^{\mathrm{TM}}$, ScienceDirect ${ }^{\circledR}$, and ISI Web of Knowledge ${ }^{\mathrm{SM}}$ are chosen in this study because they are major databases for engineering and science literatures. Most journals and conference papers are retrieved through this way. Besides these databases, Google ${ }^{\mathrm{TM}}$ is used as a second channel and the relevant project reports, software packages, and researchers' personal websites are accessible. The third source is from the university library's hardcopy collections, as some of the important journal papers do not have electronic online version (e.g. Macduff (1974) ${ }^{(3)}$ and Fujii et al. (1974) ${ }^{(4)}$ ). During our review, we also find some other review papers for relevant topics. For example, Wang et al. (2002) ${ }^{(5)}$ summarized some published literatures for assessing the ship damage and oil outflow after collision and grounding in order to develop a standard for design against accidents; Pedersen (2010) ${ }^{(6)}$ reviewed more recent literatures for estimating the frequency and consequence of collision and grounding accidents. We further doublechecked their reference list to avoid missing relevant works.

The key words for advanced search in the first step are "maritime”, "marine”, “waterway”, “navigation”, “risk”, “QRA”, “Quantitative Risk”, “FSA”, “safety”, “Formal Safety Assessment”, “collision” and "grounding”. This is followed by the filteration of irrelevant results by going through the abstracts of these literatures. After that, the most recent papers in the references list (2006 or later) are further examined, as these papers usually have a brief literature review (e.g. Montewka et al. (2010) ${ }^{(7)}$ ). Through their reference lists, we may find some literature that we might have missed 
in the first round (e.g. Kujala et al. $(2009){ }^{(8)}$ ). Table I and Table II present the retrieved literature distribution by source and by topic, respectively.

Table I. Retrieved literature distribution categorized by source

\begin{tabular}{cc}
\hline Source & Number of literature \\
\hline On-line databases & 78 \\
Internet websites & 34 \\
Library collections hardcopies & 8 \\
\hline
\end{tabular}

Table II. Retrieved literature distribution categorized by topic (some may fall in two or more topic categories)

\begin{tabular}{cc}
\hline Fields & Number of literature \\
\hline Frequency estimation & 42 \\
Consequence estimation & 48 \\
Project reports & 21 \\
General and others & 23 \\
\hline
\end{tabular}

According to the literature, we found that the QRA models could be comprised two components: accident frequency (or probability) estimation and consequence analysis. The overview is also organized in terms of the two components. Section 2 provides a detailed review of the frequency estimation models as well as their strengths and weaknesses. This is followed by studies on consequence estimation in Section 3. Discussions and recommendations are illustrated in Section 4. Concluding remarks are in Section 5.

\section{ACCIDENT FREQUENCY ESTIMATION}

Most ship accident frequency models are conducted for estimating ship collision (or grounding) frequency in a specific water area. In this Section, we first introduce the ship collision and grounding models in Sub-section 2.1. It then proceeds to some studies on frequency estimation for other accidents (e.g. fire and explosion). 


\subsection{Ship Collision and Grounding Models}

The ship collision and grounding model was initially proposed by Macduff (1974) (3) , denoted by:

$$
P=P_{a} \times P_{C},
$$

where $P$ is the probability that a vessel is involved in a collision accident during its journey passing through a particular water area; $P_{a}$ is the geometrical probability of a vessel encountering accidental scenarios, namely, the collision probability if no aversive measures are made; $P_{C}$ is the causation probability, which is the conditional probability that a collision occurs in an accidental scenario. Since then, numerous researchers contribute their efforts on causation and geometrical probability estimations, which will be introduced in Sub-sections 2.1.1 and 2.1.2.

\subsubsection{Causation Probability Estimation}

Based on eqn. (1), the collision probability can be estimated by two independent probabilities - geometrical probability, which is dependent of the geometric parameters of the water area, vessel size, traffic volume, vessel speed over ground (SOG), course over ground (COG), etc; and causation probability, which is determined by vessel mariners' operational skills, the vessel maneuverability under accidental scenarios. Accordingly, in most literatures, causation probabilities for distinct water areas are considered as a constant for the same particular accident scenario. Therefore, the causation probability can be estimated on the basis of historical data collected in different locations and then applied in the area of interest (e.g. Kaneko (2002) ${ }^{(9)}$ ). Note that the causation probabilities for different accidental scenarios are not the same. For example, according to Pedersen (1995) ${ }^{(10)}$ and Otto et 
al. (2002) ${ }^{(11)}$, the causation probabilities for ship intersection (Fig. 1), heading-on

(Fig. 2) and crossing scenarios are 1.3E-04, 4.9E-05, and 1.3E-04, respectively.

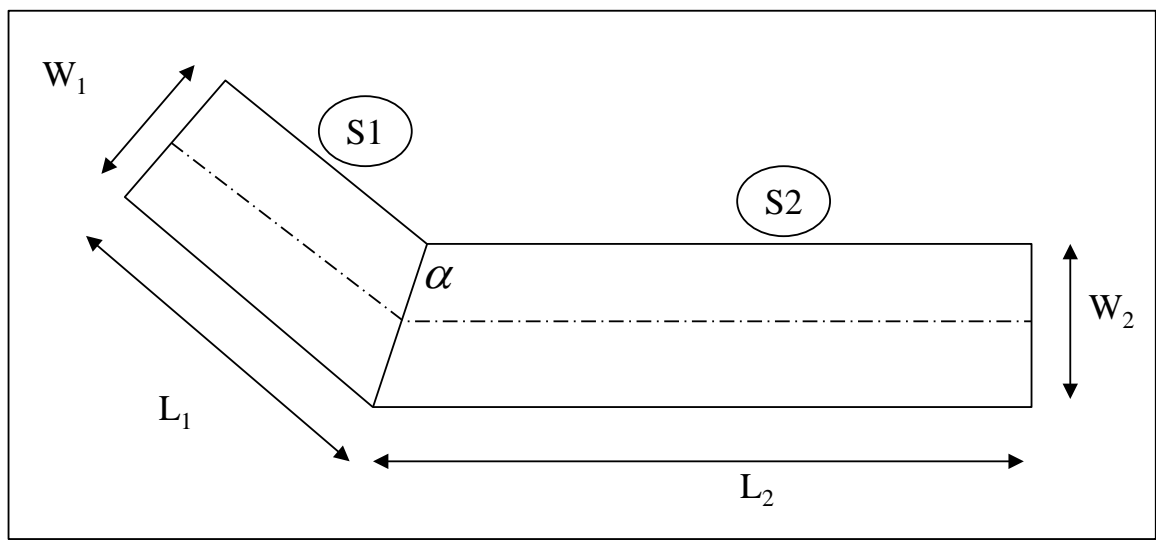

Fig. 1. Intersecting waterways collision ${ }^{(11)}$

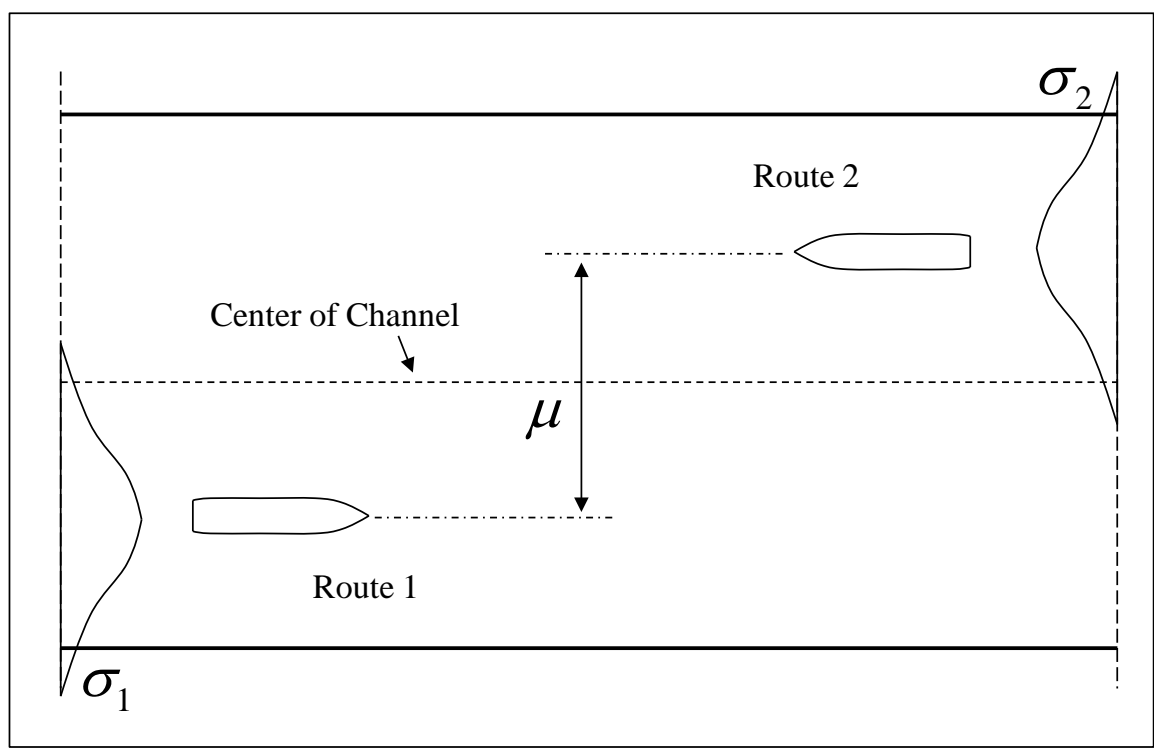

Fig. 2. Parallel head-on waterways collision ${ }^{(11)}$

The estimated causation probabilities can be applied in collision (or grounding) frequency estimation in other water areas with distinct geometrical characteristics and traffic volumes. The causation probabilities can also be applied to predict the collision (or grounding) frequency when the traffic volume has been changed in future. This is because the causation probability reflects the ability of vessels to address various types of accident scenarios and independent of traffic and geometrical characteristics. 
Several methods have been used to estimate the value of the causation probability. The simplest way is to use historical accidents statistics to calibrate the causation probability $P_{C}$, for example, Macduff (1974) ${ }^{(3)}$. This approach heavily relies on the availability of the historical accidents records. In addition, this method is not able to reflect the insightful understanding of the accidents causes. Accordingly, it would not provide supports to decision makers when the risk reduction solutions should be implemented.

Fault tree analysis method can also be used to estimate the causation probability. Fowler and Sørgard (2000) ${ }^{(12)}$ gave two detailed examples, one is the fault tree applied to derive causation probability for collision in good visibility (see Fig. 3), and the other is the fault tree applied to derive causation probability for powered grounding in good visibility. By using fault tree, the error related to human performance and the error related to incapacitation can be modelled.

Bayesian network approach, as an improvement over the fault tree analysis, can also be used to estimate causation probability. Through a carefully constructed Bayesian Network, expert judgement and historical statistics can be incorporated, in order to model the human error, human behaviour, and mechanical failure, etc. The Bayesian network is constructed by nodes and arcs. The nodes are variables that could have several different values and each value with some probability. For instance, a node could be the "Weather Condition", and the values for the "Weather Condition" could be "Good" or "Bad", and probability of the "Good" or "Bad" could be determined by historical statistics data. The probabilities of the values of a node can be affected by other node(s), through the connection of the arcs. In the Fig. 4, for instance, the node "Visibility" could be affected by the node "Weather Condition", and the node "React Time" could be affected by the node "Visibility". 
It should be noted that one fault tree could be represented by a Bayesian Network. A major advantage of the Bayesian Network over the fault tree analysis is that the size of the fault tree grows exponentially with the level of variables. For complex system, the size of fault tree often becomes too large. While the Bayesian Network remains compact even for large scale problem. Friis-Hansen and Pedersen (1998) ${ }^{(13)}$ developed a Bayesian network for a navigating officer reacts in the event of being on collision course (dangerous encounter). Pedersen (1995) ${ }^{(10)}$ and Otto et al. (2002) ${ }^{(11)}$ used a similar Bayesian network to derive the causation probabilities of various meeting scenarios (e.g., head-on, overtake, and crossing). Friis-Hansen and Simonsen (2002) (14) gave a Bayesian network that considers correlation between two approaching vessels for estimating the causation probability of ship-ship collision. Trucco et al. (2008) ${ }^{(15)}$ applied the Bayesian Network to study the risk of maritime transport system.

Besides the fault tree and Bayesian Network, the expert judgement elicitation method has also been successfully used to estimate the causation probability (Szwed et al. $\left.(2006){ }^{(16)}\right)$. In Merrick and van Dorp (2006) ${ }^{(17)}$, the probability of a collision is estimated by summing over all the possible situations:

$$
\begin{aligned}
P(\text { Collision })= & \sum_{j=1}^{k} \sum_{i=1}^{l} P\left({\text { Collision } \mid \text { Incident }_{i}}_{\text {Situation }_{j}}\right), \\
& \times P\left(\text { Incident }_{i} \mid \text { Situation }_{j}\right) \times P\left(\text { Situation }_{j}\right)
\end{aligned},
$$

where $P\left(\right.$ Situation $\left._{j}\right)$ is the probability that a particular combination of values of the factors occurs in the system; $P\left(\right.$ Incident $_{i} \mid$ Situation $\left._{j}\right)$ is the probability that a particular triggering incident occurs in the given situation; and $P\left(\right.$ Collision|Incident $_{i}$, Situation $\left._{j}\right)$ is the probability that a collision accident occurs in the defined situation once the triggering incident has occurred. Obviously, the product $P\left(\right.$ Incident $_{i} \mid$ Situation $\left._{j}\right) \times$ 
$P\left({\text { Collision} \mid \text { Incident }_{i} \text {, Situation }}_{j}\right)$ is more or less equivalent to the causation probability mentioned above. $P\left(\right.$ Situation $\left._{j}\right)$ can be obtained by using Bayesian simulation techniques, $P\left(\right.$ Incident $_{i} \mid$ Situation $\left._{j}\right)$ can be assessed by using traditional Bayesian

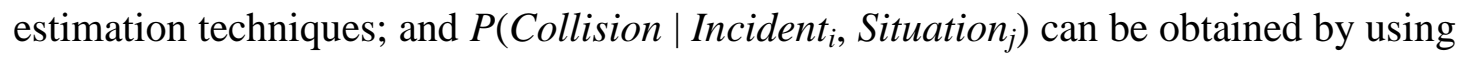
expert judgement elicitation method. The pairwise comparison approach is used to evaluate the uncertainty of expert judgments (Szwed et al. (2006) ${ }^{(16)}$ ). By using such techniques, not only the point estimation of the collision risk, but also the full distribution information about the collision risk can be obtained.

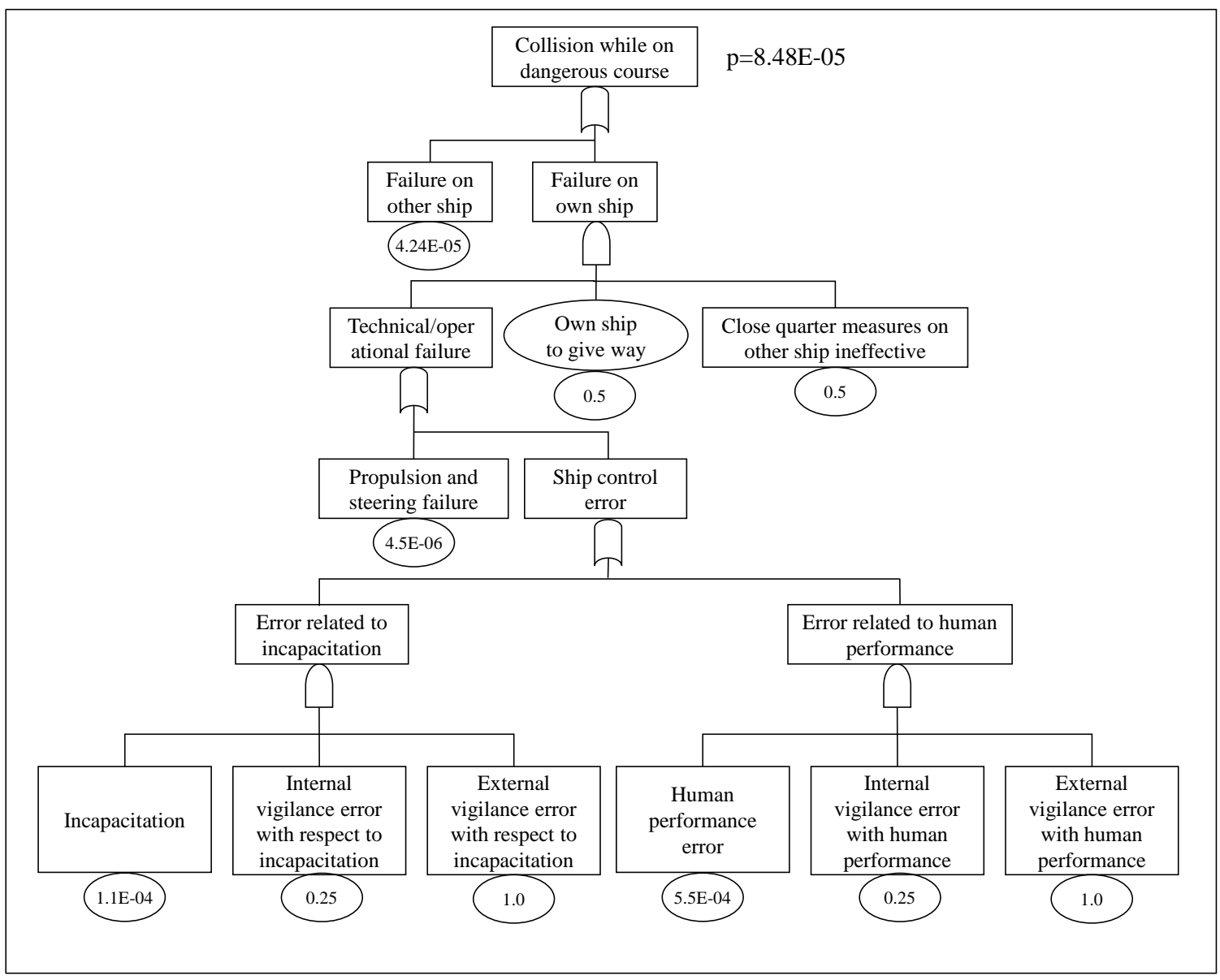

Fig. 3. Fault tree applied to derive causation probability for collision in good visibility ${ }^{(12)}$ 


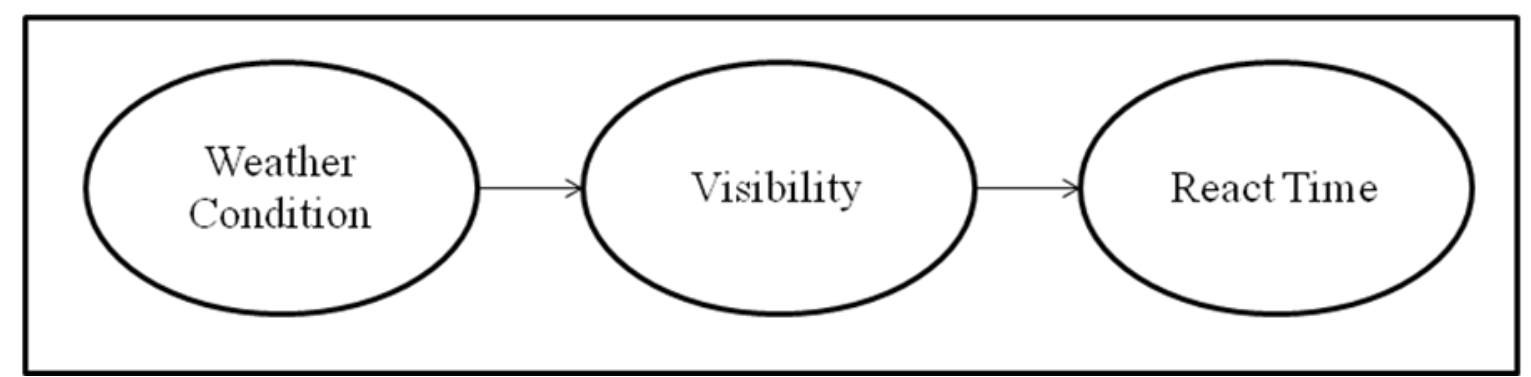

Fig. 4. Nodes and arcs of a simple Bayesian Network

\subsubsection{Geometrical Probability Estimation}

\subsubsection{Macduff's Model}

Macduff (1974) ${ }^{(3)}$ proposed two models to estimate the probabilities with respect to groundings and collisions, respectively.

Based on a Buffon's Needle Problem, the geometrical probability of hitting the walls of a channel (grounding) was estimated by

$$
P_{g}=\frac{4 T}{\pi C}
$$

where $T$ is the track length of the ship or stopping distance; $C$ is the breadth of the channel. It should be pointed out that $T$ is a function of the size and speed of the ship. However, the inappropriate assumption results in overestimation of the geometrical probability (the angle of stopping track is not appropriate to be assumed uniformly distributed between 0 and $\pi / 2$ ).

In order to estimate the geometrical probability for ship collision, molecular collision theory was applied by Macduff (1974) ${ }^{(3)}$. Based on the theory, the geometrical probability for ship collision has an approximately linear relationship with travelling distance, that is, the quotient of travelling distance out of mean free 
path (constant) is an approximation of geometrical probability ${ }^{*}$. The probability can be calculated by:

$$
P_{a}=\frac{X \cdot L}{D^{2}} \cdot \frac{\sin (\theta / 2)}{925}
$$

where $D$ is average distance between ships (in miles); $X$ is actual length of path to be considered for a single ship (nautical miles); $L$ is average vessel length (m). In this formula, a main ship stream are assumed to move with the same speed $V$ and there is a single ship approaching the stream with speed $V$ and angle $\theta$. This model can be easily expanded to more general scenarios. However, the geometrical probability is also overestimated, especially when the angle is very small. In addition, the equal speed assumption is also not reasonable and may result in underestimation. Based on the proof, the model can be extended to more complex conditions (e.g. Pedersen model $\left.^{(10)}\right)$.

\subsubsection{Fujii's Model and its Following-up}

Fujii (1971) ${ }^{(18)}$ proposed a model to estimate the average number of evasive actions by a ship passing through an area as:

$$
\int_{\text {entrance }}^{\text {exit }}\left(\rho D_{e} V_{\text {rel }} / V\right) d x \text {, }
$$

where $\rho$ is the ship density(number of ships per unit area), $D_{e}$ is the diameter of evasion, $V_{\text {rel }}$ is the relative speed, and $\mathrm{V}$ is the speed of the passing ship. The model is developed based on geometry and laws of motion. The $D_{e}$ varies from 9.5 to 16.3 times of ship length according to Fujii et al. (1974) ${ }^{(4)}$.

\footnotetext{
${ }^{*}$ The second order Taylor expansion of an exponential function is linear.
} 
The assumptions of Fujii's model is more reasonable compared to Macduff's model. However, the results show that Fujii's model also overestimates the geometrical probability (even higher than Macduff's model). This is because the evasive actions is assumed to be 9.5 to 16.3 times of ship length, which is quite conservative. In reality, minimum ship distance in some Straits (e.g. Singapore Straits) is around 3 times of the ship length.

Following Fujii's pioneering work, the concept of a ship domain was proposed and widely applied in navigational safety studies. Various types of ship domains with distinct shapes and sizes are defined by Fujii (1971) ${ }^{(18)}$, Goodwin (1975) ${ }^{(19)}$, Coldwell (1982) ${ }^{(20)}$, and Davis et al. (1982) ${ }^{(21)}$ etc. In 1993, Zhao et al. ${ }^{(22)}$ commented the existing ship domains mentioned above and proposed the concept of fuzzy ship domains. Since then, the fuzzy ship domains have been developed and applied in estimating frequencies of ship collisions ${ }^{(23-26)}$. Szlapczynski (2006) ${ }^{(23)}$ proposed a measure of collision risk based on the concept of ship domain, which is an extension of earlier works ${ }^{(20-22,27)}$.

\subsubsection{Pedersen's Model}

Pedersen and his research collabroators conducted a series of studies and provided further approaches to estimate geometrical probability ${ }^{(10)}$, which has been applied in several later research works ${ }^{(11,28,29)}$.

Pedersen's model assumes that there are two crossing waterways, waterway 1 and 2 (as shown in Fig. 5), and the traffic intensity (number of ships passing per unit time), velocity, ship routes’ lateral distributions are all known. Pedersen $(1995){ }^{(10)}$ reported that the number of ships belonging to class $j$ on collision course with one ship of the class $i$ in waterway 1 during the time $\Delta t$ in a segment $d z_{j}$ of water 2 is 


$$
P_{\Delta t}=\frac{Q_{j}^{(2)}}{V_{j}^{(2)}} f_{j}^{(2)}\left(z_{j}\right) D_{i j} V_{i j} d z_{j} \Delta t
$$

where $Q_{j}$ the number of movements of ship class $j$ per unit time; $z$ is the distance from the centerline of the waterway; the lateral distribution of the ship routes is denoted by $f$, which is often taken to be normal distribution; $V_{i j}$ is the relative velocity, calculated by

$$
V_{i j}=\sqrt{\left(V_{i}^{(1)}\right)^{2}+\left(V_{j}^{(2)}\right)^{2}-2 V_{i}^{(1)} V_{j}^{(2)} \cos \theta}
$$

and $D_{i j}$ is the collision diameter, represented by

$$
D_{i j}=\frac{L_{i}^{(1)} V_{j}^{(2)}+L_{j}^{(2)} V_{i}^{(1)}}{V_{i j}} \sin \theta+B_{j}^{(2)}\left\{1-\left(\sin \theta \cdot \frac{V_{i}^{(1)}}{V_{i j}}\right)^{2}\right\}^{1 / 2}+B_{i}^{(1)}\left\{1-\left(\sin \theta \cdot \frac{V_{j}^{(2)}}{V_{i j}}\right)^{2}\right\}^{1 / 2},
$$

where $L_{i}^{(1)}$ is the length of vessel with ship class $i$ in the waterway $1, L_{j}^{(2)}$ is the length of vessel with ship class $j$ in the waterway $2 . B_{i}^{(1)}$ is the width of vessel with ship class $i$ in the waterway $1, B_{j}^{(2)}$ is the length of vessel with ship class $j$ in the waterway 2 . $V_{i}^{(1)}$ is the velocity of vessel with ship class $i$ in the waterway $1, V_{j}^{(2)}$ is the velocity of vessels with ship class $j$ in the waterway 2 and $\theta$ is the angle between the directions of the two waterways. 


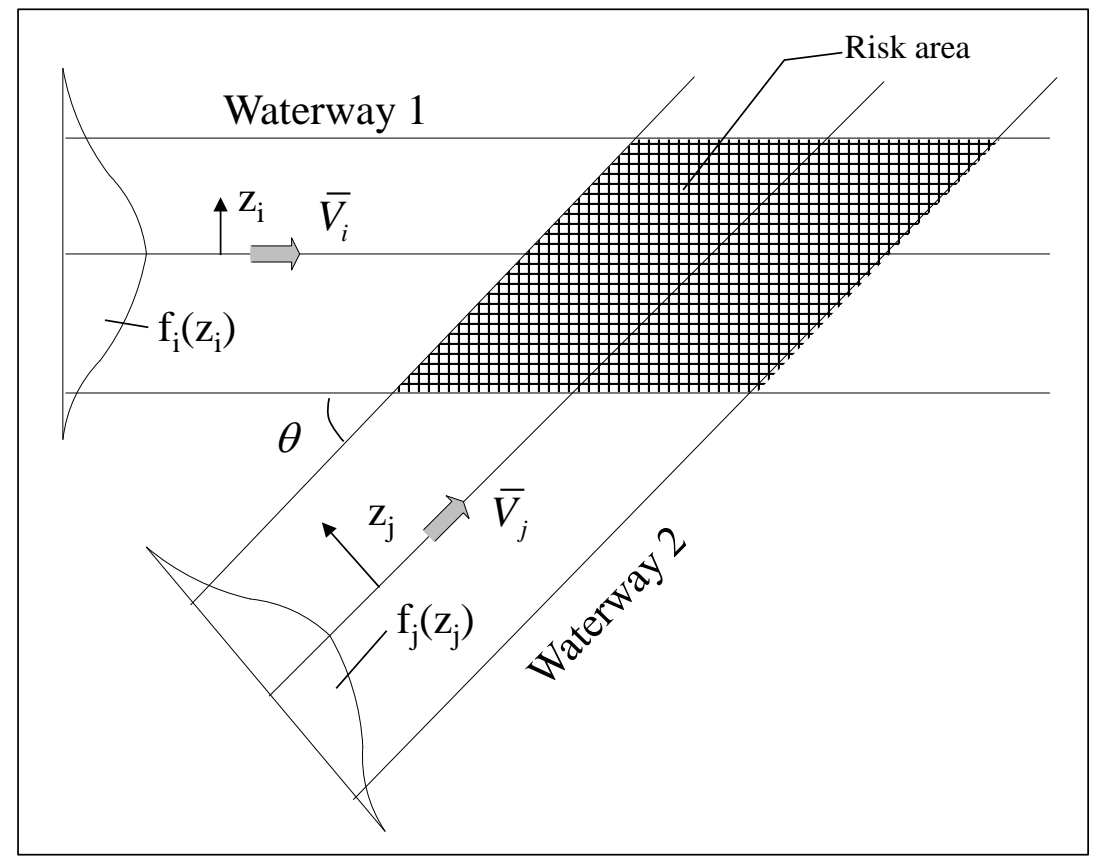

Fig. 5. Crossing waterways collision ${ }^{(11)}$

The geometrical probability can be estimated by,

$$
N_{a}=\sum_{i} \sum_{j} \int_{\Omega\left(Z_{i} Z_{j}\right)} \frac{Q_{i}^{(1)} Q_{j}^{(2)}}{V_{i}^{(1)} V_{j}^{(2)}} f_{i}^{(1)}\left(z_{i}\right) f_{j}^{(2)}\left(z_{j}\right) V_{i j} D_{i j} d A \Delta t,
$$

where $A$ is the considered sea area.

It should be pointed out that, different from Fujii's model using ship density in terms of number of ships per unit area, Pedersen's model uses traffic volume $Q$ (ship flow per unit time) in eqns. (6) and (9).

Pedersen provides a comprehensive approach to estimate the geometrical probability. Based on a more practical assumption, the vessels are categorized based on their distances from the predetermined navigational course (centerline), which takes the vessel meandering navigation into account using probability theory. However, how to determine the probability distribution and characteristics is challenging, as the ship movement data are not easy to be obtained. 
Kaneko ${ }^{(9)}$ proposed his models on geometrical probability estimation for two specific scenarios. One scenario is circular boundary area with random sailing direction and the other is rectangular boundary with fixed sailing direction. When the distance between two ships is smaller than $r$, a dangerous encounter situation is counted. For the circular boundary and random sailing direction scenario, the number of ships encountered by one ship within time $T$ is

$$
\lambda_{c}=\frac{4 \rho V r T}{\pi}(1+\alpha) E\left(\frac{2 \sqrt{\alpha}}{1+\alpha}\right),
$$

and

$$
E\left(\frac{2 \sqrt{V_{0} V}}{V+V_{0}}\right)=\int_{0}^{\frac{\pi}{2}} \sqrt{1-\frac{4 V_{0} V}{V+V_{0}} \sin ^{2} \theta} d \theta
$$

where $\rho$ is the average number of sailing ships in the area. $V$ is velocity of other ships, $\alpha=V_{0} / V$, and $V_{0}$ is velocity of own ship. $\theta$ is the angle between the directions of own ship and other ships. For the rectangular boundary with fixed sailing direction scenario, the number of ships encountered by one ship within time $T$ is

$$
\lambda_{c}=\rho V 2 r T \sqrt{1+\alpha^{2}+2 \alpha \cos \theta} .
$$

It is also shown that the random sailing direction scenario results in $10 \%$ more dangerous encounters than the fixed direction scenario. As the ship traffic density within a large sea area is assumed to be uniform, Kaneko’s model is more appropriate to be used in wide open sea area rather than in restricted narrow waterway.

\subsubsection{COWI Models}

A practical mathematical model was applied in report by COWI ${ }^{(30)}$ to calculate ship collision frequency. For parallel scenarios (head-on or overtaking, see Fig. 6 and 7), the collision frequency depends on length of the route segment, traffic intensity in 
each of the two directions, width and speed of the ships, deviation of the ships from the route axis, and causation probability $P_{C}$.

The frequency of two ships colliding in parallel waterways is

$$
P_{X}=P_{T} \times P_{G} \times P_{C} \times k_{R R},
$$

where $P_{T}$ is yearly frequency of meeting within one route segment (a matter of time and route length), $P_{T}=L N_{1} N_{2}\left|\frac{V_{1}-V_{2}}{V_{1} V_{2}}\right|, L$ is the length of route segment, $N_{1}$ is the yearly number of ship 1 passing, $N_{2}$ is the yearly number of ship 2 passing, $V_{1}$ is the speed of ship1, and $V_{2}$ is the speed of ship2. $P_{G}$ is geometrical collision probability (a matter of width), $P_{G}=\frac{B_{1}+B_{2}}{C}, B_{1}$ is the breadth of ship $1, B_{2}$ is the breadth of ship 2, and $c$ is the width of the segment. $P_{C}$ is the causation probability, and it is taken to be 3E-04 in the report. $k_{R R}$ is risk reduction factor, and it is taken to be 0.5 .

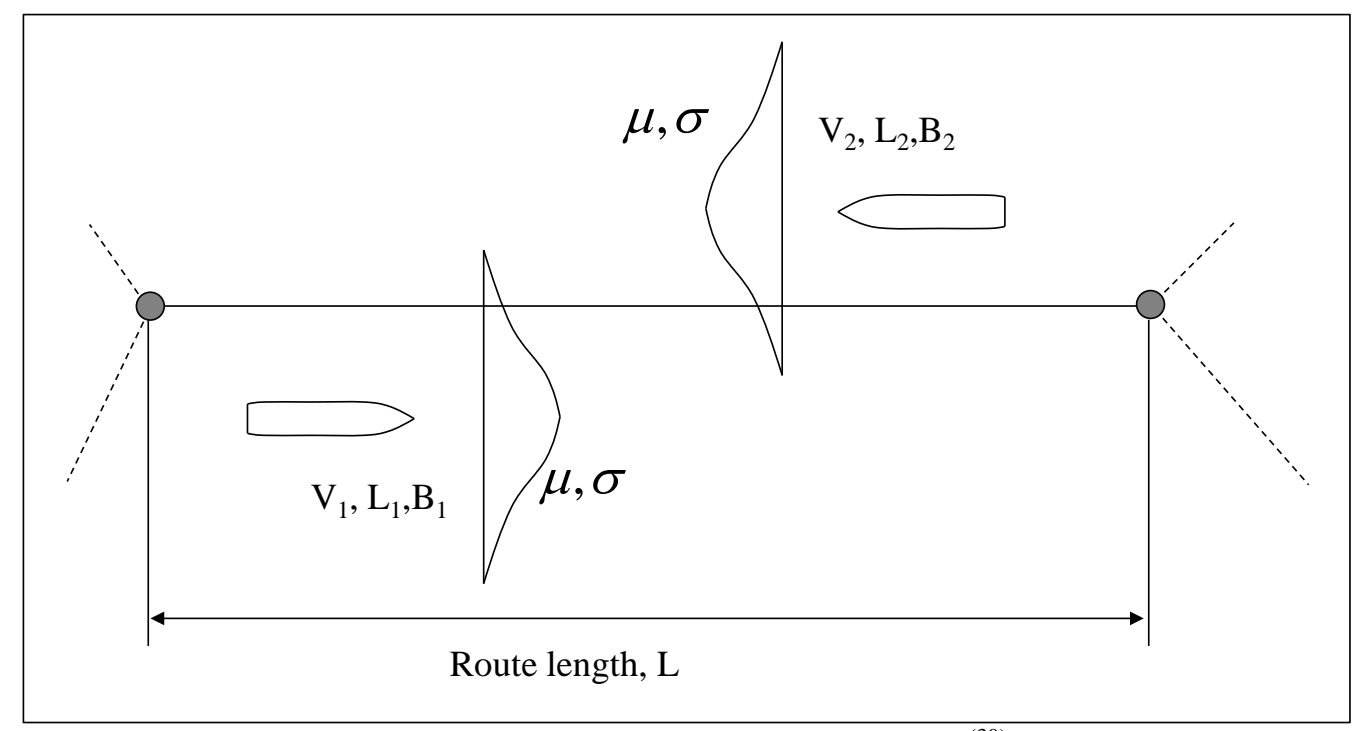

Fig. 6. Head-on parallel collision scenarios ${ }^{(30)}$ 


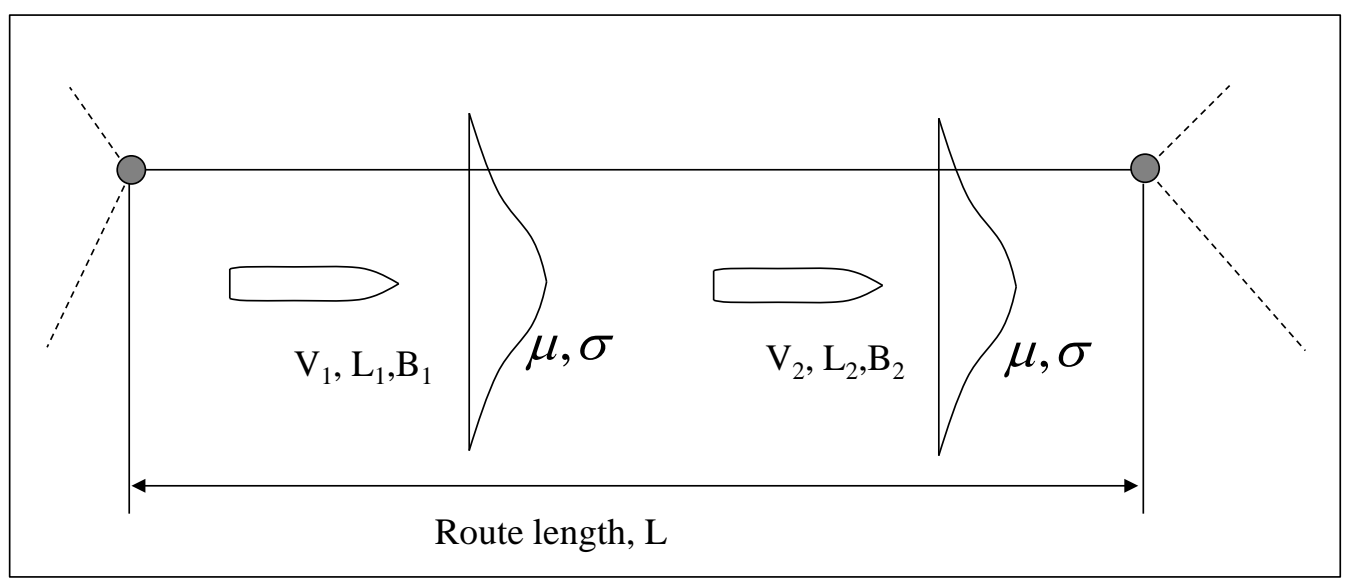

Fig. 7. Overtaking parallel collision scenarios ${ }^{(30)}$

Crossing collision frequency depends on crossing pattern (X-type or Y-type, see Fig. 8), traffic intensity in each of the two directions, width, length and speed of the ships, crossing angle, causation probability $P_{C}$, probability that the traces of both ships intersect.

And the frequency is calculated by,

$$
P_{X}=P_{I} \times P_{G} \times P_{C} \times k_{R R},
$$

where $P_{I}$ is the probability that the traces of the two ships intersect, for X-type crossing $P_{I}=1$, for Y-type crossing with intersection $P_{I}=1$, and for Y-type crossing without intersection $P_{I}=0$. If it is not clear whether there are intersections, for $\mathrm{Y}$ type crossing $P_{I}=0.5 . P_{G}$ is the geometrical collision probability, which depends on the so-called critical time interval $\Delta t$ (see Fig. 7), $P_{G}=N_{1}\left(1-e^{-N_{2} \Delta t}\right)$ and

$$
\Delta t=\frac{1}{\left|V_{1} V_{2}\right|}\left[B_{2}\left|\frac{V_{2}}{\sin \theta}-\frac{V_{1}}{\tan \theta}\right|+B_{1}\left|\frac{V_{1}}{\sin \theta}-\frac{V_{2}}{\tan \theta}\right|+L_{1}\left|V_{2}\right|+L_{2}\left|V_{1}\right|\right] .
$$

The causation probability $P_{C}$ is taken to be 3E-04. If one of the two potentially colliding ships has pilot service (or local experience or heightened safety standards), the risk reduction factor $k_{R R}=0.75$. If both ships have the risk reduction measures, $k_{R R}=0.5$. 
The model used in COWI report is based on similar concept of the Pedersen's model. It further considers some risk reduction factors, which add more flexibility to the model. Nevertheless, the risk reduction factors are determined in a somehow subjective way.

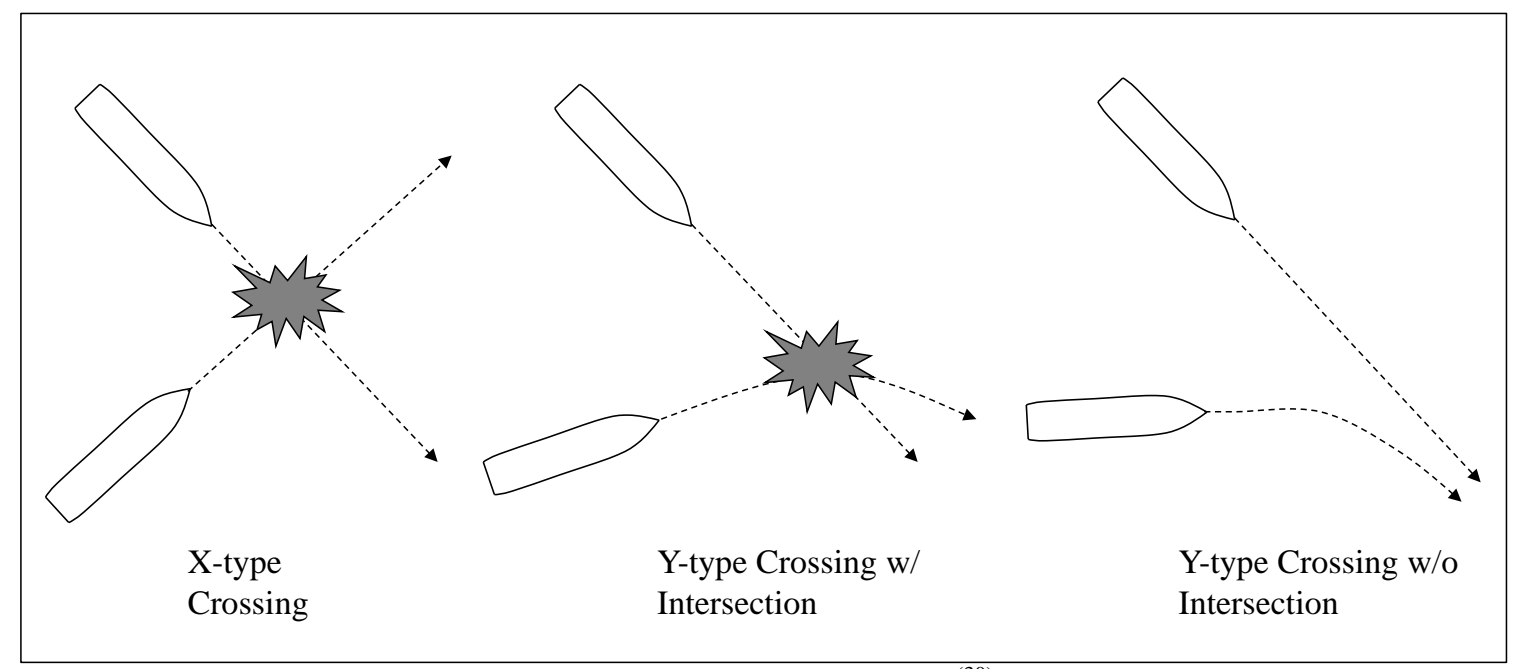

Fig. 8. Crossing collision patterns ${ }^{(30)}$

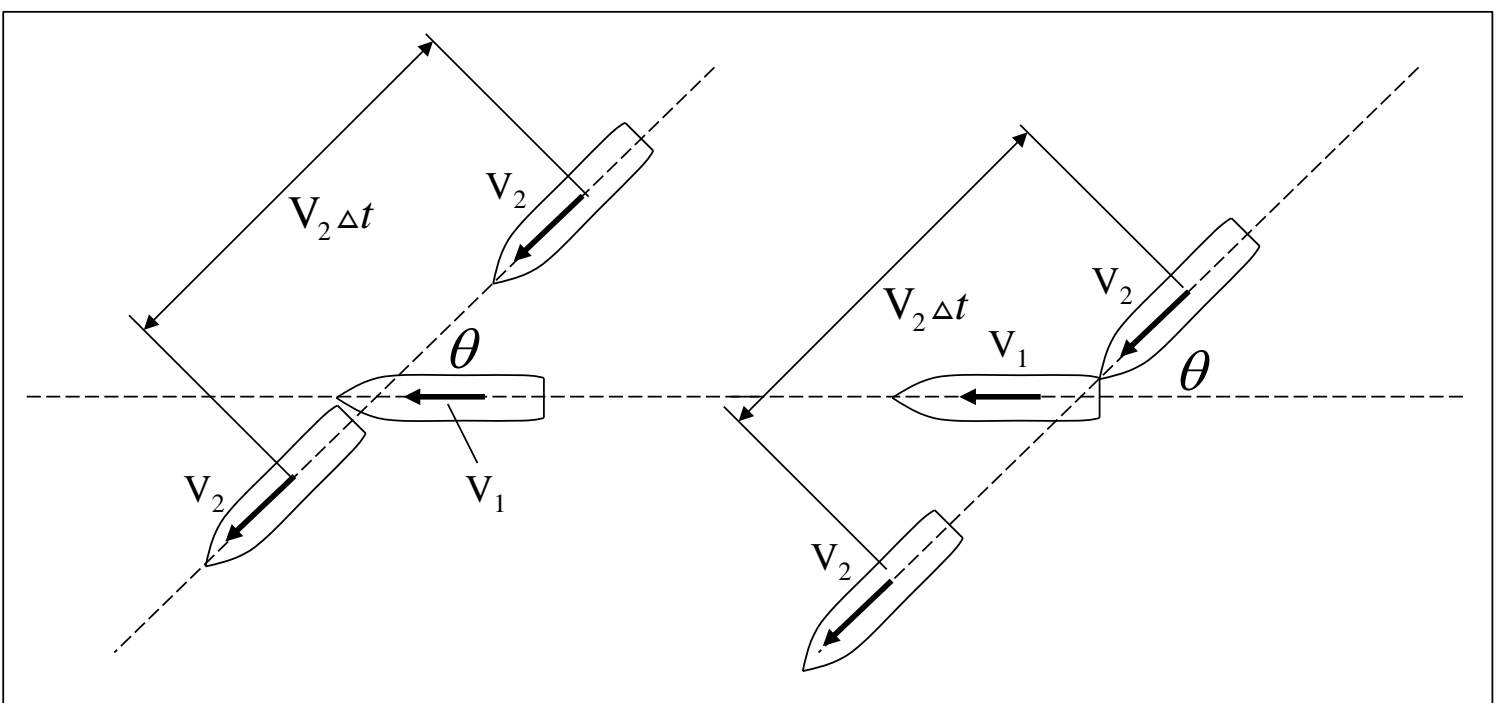

Fig. 9. Geometrical determination of the critical time interval/route length for a crossing collision ${ }^{(30)}$

COWI ${ }^{(30)}$ presented a similar grounding/contact model. Two patterns are considered, one is called grounding due to imprecise navigation, and the other is called grounding due to missed turn (Fig. 10). The frequency of grounding due to imprecise navigation is 


$$
P_{X}=P_{G} P_{C} k_{R R} k_{D C},
$$

and

$$
P_{G}=F\left(\alpha_{1}\right)-F\left(\alpha_{2}\right),
$$

where $\alpha_{1}$ is the upper bound of the critical angle, $\alpha_{2}$ is the lower bound of the critical angle, and $F$ is ship course lateral distribution. The causation factor $P_{C}$ is $3 E-04$; the distance factor $k_{D C}$ is $\frac{10 \mathrm{~nm}}{\text { distance }}$; and the risk reduction factor $k_{R R}$ is 0.5 . The frequency of grounding due to missed turn is

$$
\begin{gathered}
P_{X}=P_{N T} P_{G} P_{C} k_{R R}, \\
P_{G}=F\left(\alpha_{1}\right)-F\left(\alpha_{2}\right),
\end{gathered}
$$

and

$$
P_{N T}=e^{-\lambda \frac{x}{V}}
$$

where $P_{N T}$ is the annual frequency that a ship misses a turn and does not correct its error at a later but sufficiently early point, $\lambda$ is checking frequency ( 0.5 to 1 minute), $x$ is the distance between missed turning point and ground, and $V$ is vessel speed. The causation factor $P_{C}$ is $3 \mathrm{E}-04$; and the risk reduction factor $k_{R R}$ is 0.5 . 


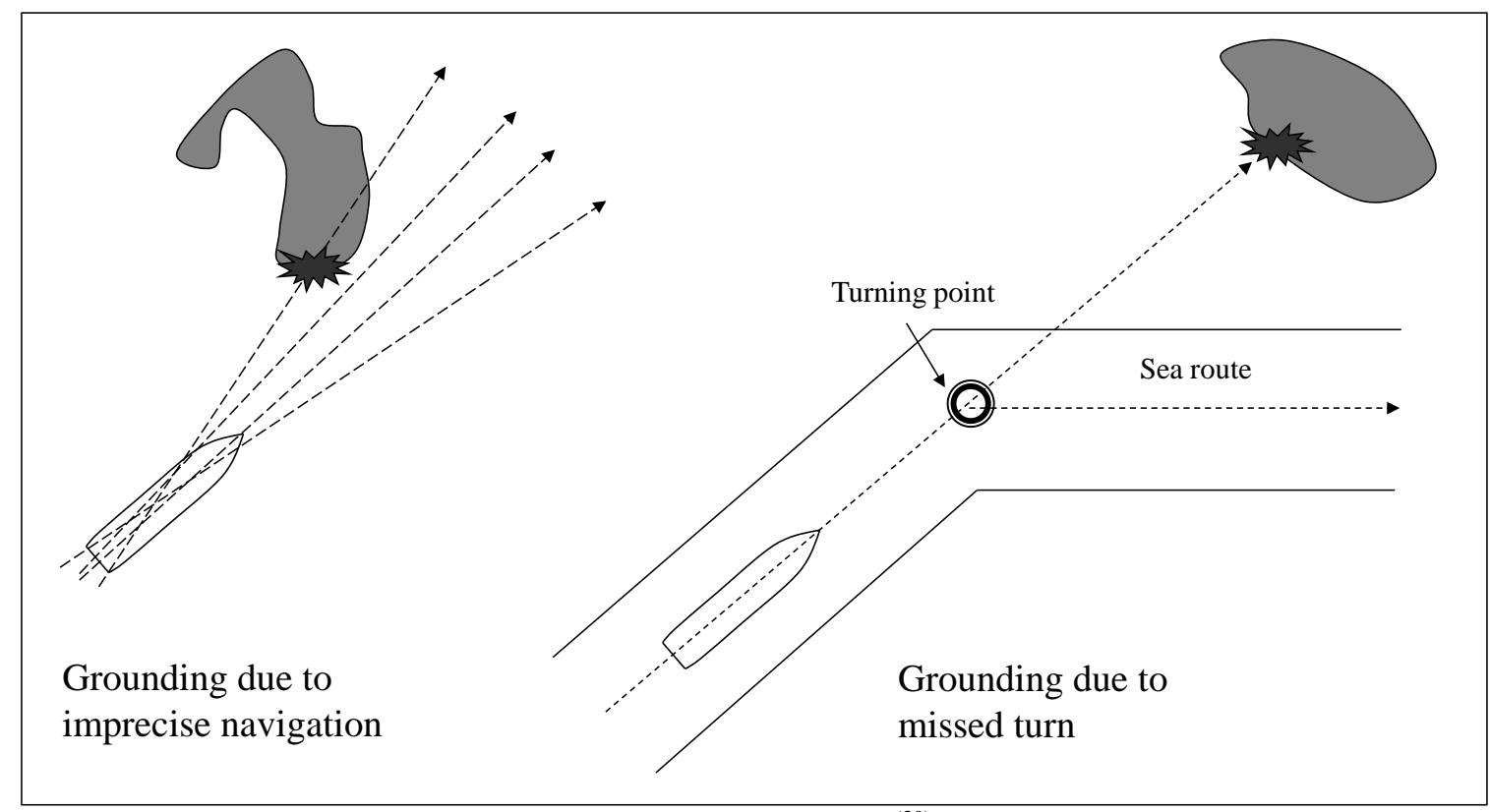

Fig. 10. Grounding due to imprecise navigation and missed turn ${ }^{(30)}$

In COWI models, the geometrical probability is further divided into several independent probabilities. Compared to Pedersen's Models, the models are friendlier to be used in practical projects due to the better data availability of its input parameters.

\subsubsection{Other Models}

In addition to the above mentioned models, several new models are also developed by researchers. A simple random walk model was built in Tan and Otay (1999) ${ }^{(31)}$ to estimate the geometrical probability. Roeleven et al. (1995)

calculated the accident probability by fitting generalized linear models. Geng et al. (2009) ${ }^{(33)}$ fitted the distributions of vessel courses by field observations, and then calculate the vessel-bridge collision probability. Debnath and Chin ${ }^{(34)}$ (2009) and Chin and Debnath (2009) ${ }^{(35)}$ studied perceived collision risk in port water.

\subsubsection{Computer Simulation}


Although the causation probability based mathematical models for estimating accident frequency have been well studied and successfully applied in real world projects, they have some inherent limitations. These models assume that a ship will appear in a certain location with a certain probability, and due to the large amount of ships in the study area, it is often assumed that the appearances of all the ships follow one or few certain probability distribution(s) in a given location at any time (e.g. uniform, normal distributions), which is unrealistic for restricted waters. They would not be appropriate to be applied in waters with some navigational regulations. For example, the ferry services often operate regularly in day time and cease operation at night, and VLCCs (very-large crude carriers) may only pass a narrow waterway during high tide times. The causation based mathematical models cannot catch the time-dependent patterns well. In this case, the computer simulation could be a better alternative. The maritime simulation model is on the basis of an interaction counting model, which are similar in approach to the geometrical probability estimations.

A joint research group involved three universities - The Geoge Washington University, Rensselear Polytechnic Institute, and Virginia Commonwealth University, i.e. GWU-RPI-VCU group for short, developed a counting model that considers each vessel of interest and each other vessel in the simulation ${ }^{(36)}$. For each pairing, the closest point of approach (CPA) is calculated, along with the angle of interaction and the time to the CPA. The model has been widely applied by the group to assess and/or manage the risks (e.g. the Washington State Ferries). This methodology has been developed and continuously improved over a span of more than 10 years by the group (17, 36-44). It should be pointed out that the methodology allows for the effectiveness evaluation of a simultaneous implementation of the likelihoods and consequences of various accidental scenarios. The framework of the risk management is summarized 
as a six-step procedure. The first step is to define a quantitative measure of risk. The second step is to identify potential risk interventions and determine their impact on the accidental events. The third step is to develop a comprehensive quantitative model for comparing the risk interventions in a meaningful manner. The fourth step is to establish a baseline level of risk by defining a baseline scenario and using the developed model to quantify its risk. The fifth step is to model the effect of all the risk interventions in terms of changes to model parameters. The final step is to implement these changes to the model and evaluate the risk interventions relative to the established baseline level of risk.

Another separate team from Bogacizi University takes a different approach for the narrower waterways that is of less computational time. They simply partition the waterway into slices (or cells) and take each vessel of interest and count an interaction for all other vessels in the same slice (Uluscu et al. $(2009){ }^{(45)}$ ). The model has been applied to assess the risk of the Strait of Istanbul. Several attributes, such as vessel type \& length, vessel reliability (age \& flag), pilot request, tug request, vessel proximity, visibility condition, current, geographical difficulty, and local traffic density are taken into account in their model.

Hong Kong Marine Department ${ }^{(46)}$ briefly presented a risk assessment project for the Hong Kong port waters. Firstly, a comprehensive analysis of marine traffic activities within Hong Kong waters was conducted by capturing the latest traffic activity via field surveys. Secondly, the study built a marine traffic risk assessment simulation model, and the risk of future scenario was compared with the baseline scenario.

Qu and Meng (2011) ${ }^{(47)}$ proposed a Cellular Automata model based simulation approach for the Singapore Strait. Discrete event models are applied to generate 
vessels with different categories and velocities from four portals of the Straits. 10 Ship following rules and 5 ship crossing rules are used to simulate the mariners' response to various navigational scenarios. This is the first attempt to apply the relatively mature roadway vehicle movement simulation models in maritime transportation by taking into account the ship interactions. The model can be used to generate the lateral distributions of the ship trajectory (for Pedersen's model) and to estimate the ship domain violation (for Fujii’s model).

\subsection{Fire/Explosion and Other Accident Frequency Estimation}

The frequency of fire and explosion accidents are estimated by using historical records are applied. The literature introduced below covers the statistics of most historical fire and explosion accidents.

Fowler and Sørgaird ${ }^{(12)}$ reported fire and explosion frequency of tankers, bulk ships, general cargo ships, and ferries based on Lloyd's Maritime Information Services (LMIS) casualty database, see Table III.

Table III. Fire and Explosion Frequencies (Number of Accidents per Ship-hour) ${ }^{(12)}$

\begin{tabular}{cc}
\hline Ship type & Frequency \\
\hline Tankers & $4.08 \mathrm{E}-07$ \\
Bulk ships & $3.43 \mathrm{E}-07$ \\
General cargo ships & $2.65 \mathrm{E}-07$ \\
Ferries & $3.51 \mathrm{E}-07$ \\
\hline
\end{tabular}

IMO reported historical accident frequency statistics of various types of ships worldwide $^{(2,48-51)}$, covering the period of 1990 s to 2007 , see tables IV, V, VI, VII, and VIII. Among the results, the frequency of fire and explosion are carried out.

Table IV. Estimated frequency of initiating events for crude oil ships ${ }^{(2)}$

\begin{tabular}{cc}
\hline Initial event & Frequency of accident (per ship-year) \\
\hline Collision & $1.03 \mathrm{E}-02$ \\
Contact & $3.72 \mathrm{E}-03$ \\
Grounding & $7.49 \mathrm{E}-03$
\end{tabular}


Fire

Explosion

NASF
3.65E-03

$1.90 \mathrm{E}-03$

Double Hull (DH) ships: 1.93E-03,

Table V. Estimated frequency of initiating events for container ships ${ }^{(48)}$

\begin{tabular}{cc}
\hline Accident scenario & Accidents frequency (per ship year) \\
\hline Collision & $1.61 \mathrm{E}-02$ \\
Contact & $3.65 \mathrm{E}-03$ \\
Grounding & $6.84 \mathrm{E}-03$ \\
Fire/explosion & $3.55 \mathrm{E}-03$ \\
Heavy weather & $2.64 \mathrm{E}-03$ \\
\hline
\end{tabular}

Table VI. Estimated frequency of initiating events for various ship types ${ }^{(49)}$

\begin{tabular}{|c|c|c|c|c|c|c|}
\hline Accid & $\begin{array}{c}\text { SH } \\
\text { Oil } \\
\text { tanker }\end{array}$ & $\begin{array}{c}\text { DH } \\
\text { Oil } \\
\text { tanker }\end{array}$ & $\begin{array}{c}\text { Oil/Chemic } \\
\text { tanker }\end{array}$ & $\begin{array}{c}\text { Chemical LPG } \\
\text { tanker tanker }\end{array}$ & $\begin{array}{c}\text { Bulk } \\
\text { carrier }\end{array}$ & $\begin{array}{l}\text { LNG } \\
\text { carrier }\end{array}$ \\
\hline Coll & $9.90 \mathrm{E}-03$ & $8.60 \mathrm{E}-03$ & $\begin{array}{l}3.30 \mathrm{E}-02 \\
\end{array}$ & $9.40 \mathrm{E}-032.20$ & 1.90 & $6.70 \mathrm{E}-03$ \\
\hline Contact & $4.90 \mathrm{E}-03$ & $3.10 \mathrm{E}-03$ & 1.2 & $4.60 \mathrm{E}-033.0$ & 1.1 & $2.80 \mathrm{E}-03$ \\
\hline e/ Explosion & 3.70E-03 & $1.10 \mathrm{E}-03$ & $3 \quad 1.10 \mathrm{E}-02$ & 4.50E-03 4.30E-03 & $2.90 \mathrm{E}-03$ & $3.50 \mathrm{E}-03$ \\
\hline
\end{tabular}

Table VII. Historical accident statistics of various initiating events for cruise ships ${ }^{(50)}$

\begin{tabular}{|c|c|c|c|c|c|c|}
\hline & Collision & Contact & Grounding & Fire/Exp. & Other & SUM \\
\hline $\begin{array}{l}\text { LMIS accidents } \\
\text { recorded 1990-2004 }\end{array}$ & 8 & 2 & 17 & 16 & 34 & 77 \\
\hline $\begin{array}{l}\text { Ship years 1990- } \\
2004 \text { [ship years] }\end{array}$ & 1,742 & 1,742 & 1,742 & 1,742 & 1,742 & 1,742 \\
\hline $\begin{array}{c}\text { Cruise ship accident } \\
\text { frequency } \\
\text { [per ship year] }\end{array}$ & 4.6E-03 & 1.2E-03 & 9.8E-03 & $9.2 \mathrm{E}-03$ & 2.0E-02 & 4.4E-02 \\
\hline $\begin{array}{l}\text { Return period } \\
\text { [no. of ship years } \\
\text { per accident] }\end{array}$ & 218 & 871 & 102 & 109 & 51 & 23 \\
\hline $\begin{array}{c}\text { Number of } \\
\text { fatalities, } 1990- \\
2004\end{array}$ & 0 & 0 & 0 & 21 & 1 & 22 \\
\hline
\end{tabular}

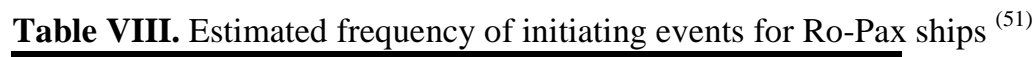

\begin{tabular}{ccc}
\hline & \multicolumn{2}{c}{$\begin{array}{c}\text { Frequency (per ship year) } \\
\text { Total }\end{array}$} \\
Serious \\
\hline Collision & $1.25 \mathrm{E}-02$ & $1.29 \mathrm{E}-03$ \\
Contact & $1.25 \mathrm{E}-02$ & $1.36 \mathrm{E}-03$ \\
Fire/Exp. & $8.28 \mathrm{E}-03$ & $3.23 \mathrm{E}-03$ \\
Wrecked/Stranded & $9.57 \mathrm{E}-03$ & $3.04 \mathrm{E}-03$ \\
Hull Damage & $2.26 \mathrm{E}-03$ & $4.53 \mathrm{E}-04$
\end{tabular}




\begin{tabular}{ccc} 
Foundered & $1.29 \mathrm{E}-04$ & $1.29 \mathrm{E}-04$ \\
Machinery Damage & $1.87 \mathrm{E}-02$ & $2.00 \mathrm{E}-03$ \\
Miscellaneous & $4.07 \mathrm{E}-03$ & $1.94 \mathrm{E}-04$ \\
\hline
\end{tabular}

\section{ACCIDENT CONSEQUENCE ESTIMATION}

\subsection{Event Tree Analysis for Consequences Estimation}

The event trees for maritime risk analysis are usually developed by specialized professional consulting firms or international organization, such as DNV (Det Norske Veritas) and IMO, based on expert judgment and historical data.

In 2007-2009, IMO published a series of FSA (Formal Safety Assessment) reports $(2,48-51)$ on the risk assessment of various types of vessels, such as container ships, crude oil tankers, cruise ships, LNG carriers, Ro-Pax ships, and dangerous goods transport with open-top container vessels. Event tree analysis is applied in all these reports to fractionize the accidental event into a number of scenarios with distinct consequences. In addition, Ronza et al. (2003) ${ }^{(52)}$ also constructed event trees for consequences estimation by historical data analysis.

Some conceptual event tree structures from the IMO's FSA reports ${ }^{(2,48-51)}$ are given in Figs. $11-15^{\dagger}$. Note that the event tree structures are different for distinct vessel types and accident categories. Major factors affecting the accident consequences are vessels speed (operational state), damage extent, survivability (sink or stay afloat), evacuation model, and dangerous cargo leakage model (depends on vessel types and cargo types).

The series of IMO's FSA reports laid solid foundations for the vessels risk assessment. The event trees developed in the reports provides a guideline for further research. However, due to the complexity and the large amount of expert domain

\footnotetext{
${ }^{\dagger}$ The high level risk models’ style was originally proposed by Vanem et al (2007) ${ }^{(53)}$.
} 
knowledge and other resources for developing the event trees, it is not possible for other researchers to validate the results obtained in these results.

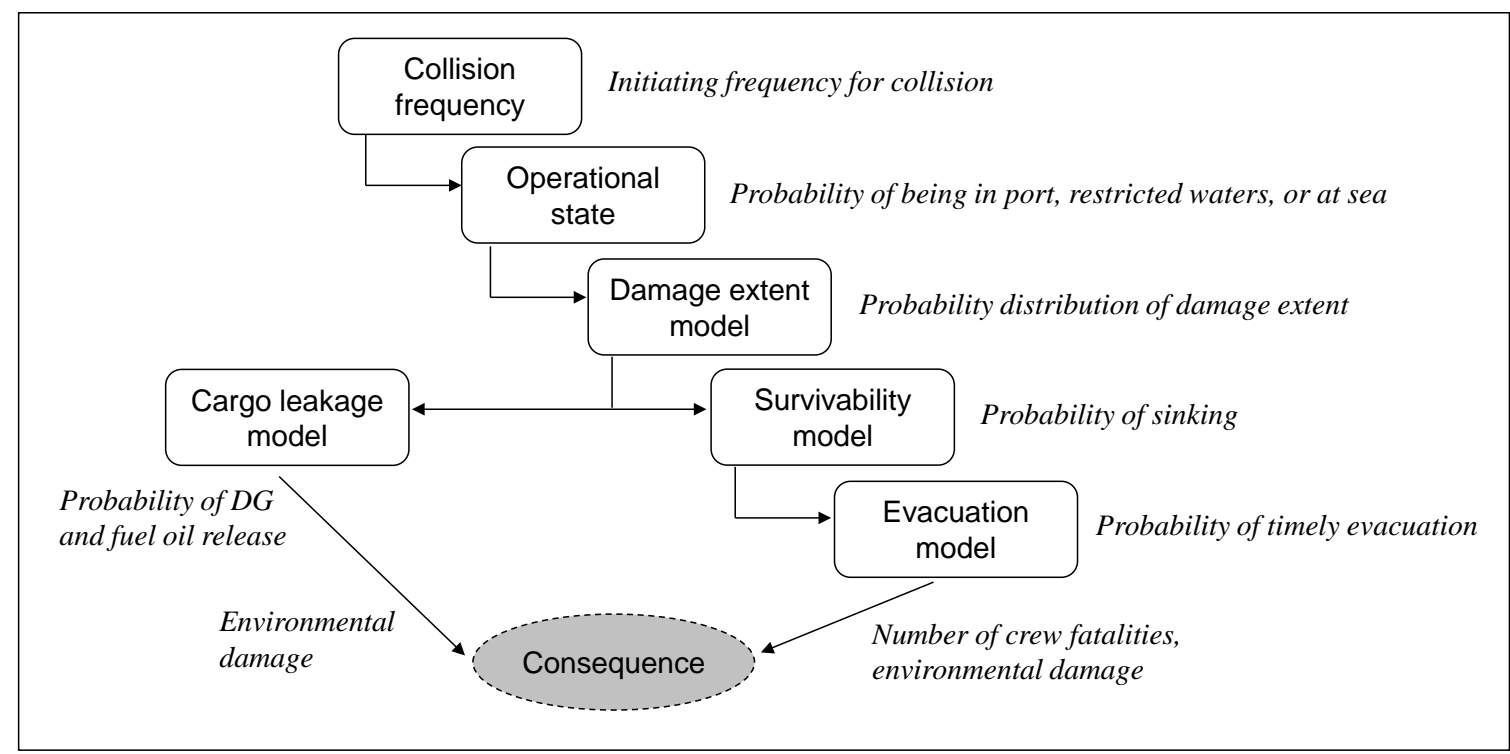

Fig. 11. High level risk model for collision scenario, container ship ${ }^{(48)}$

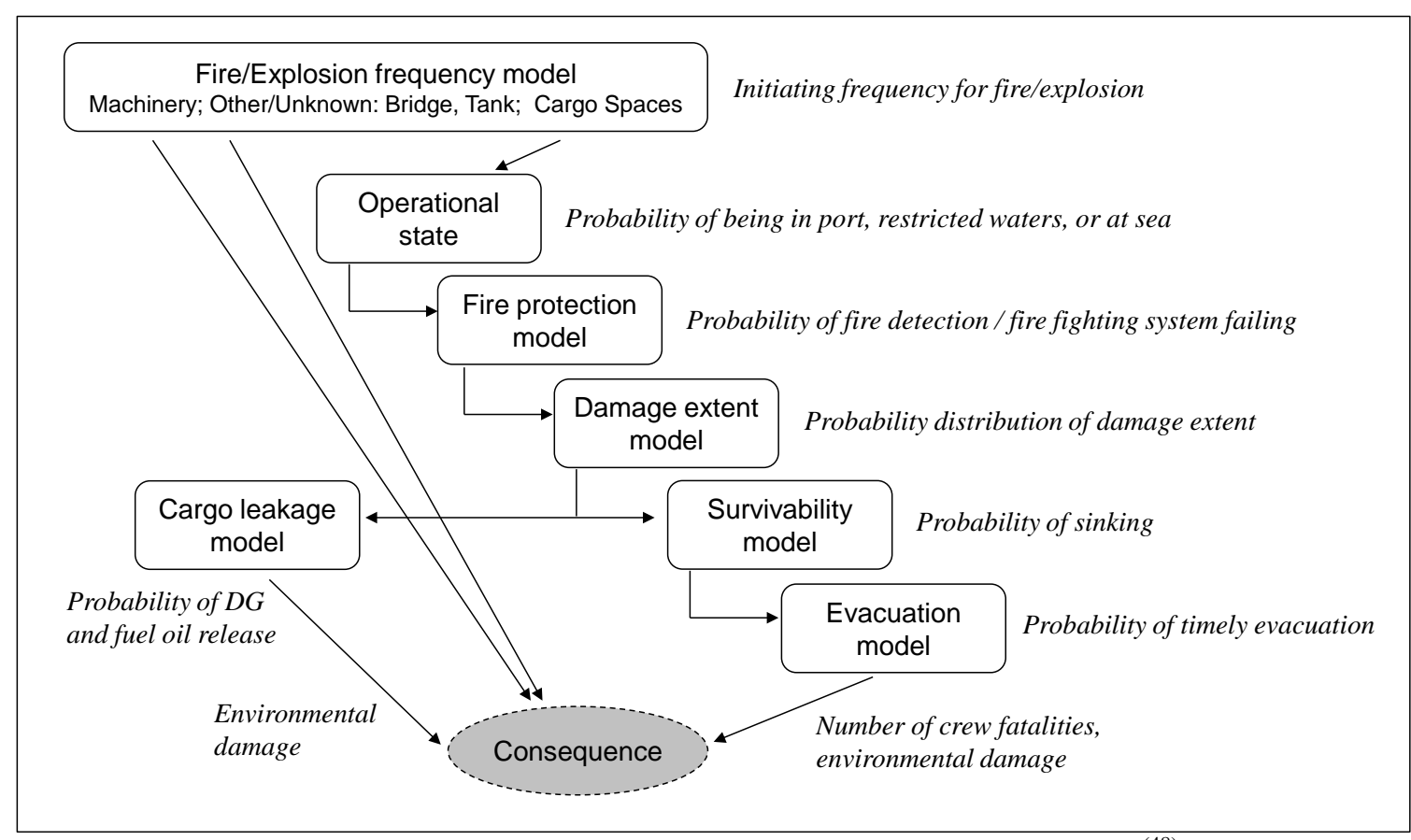

Fig. 12. High level risk model for fire/explosion scenario, container ship ${ }^{(48)}$ 


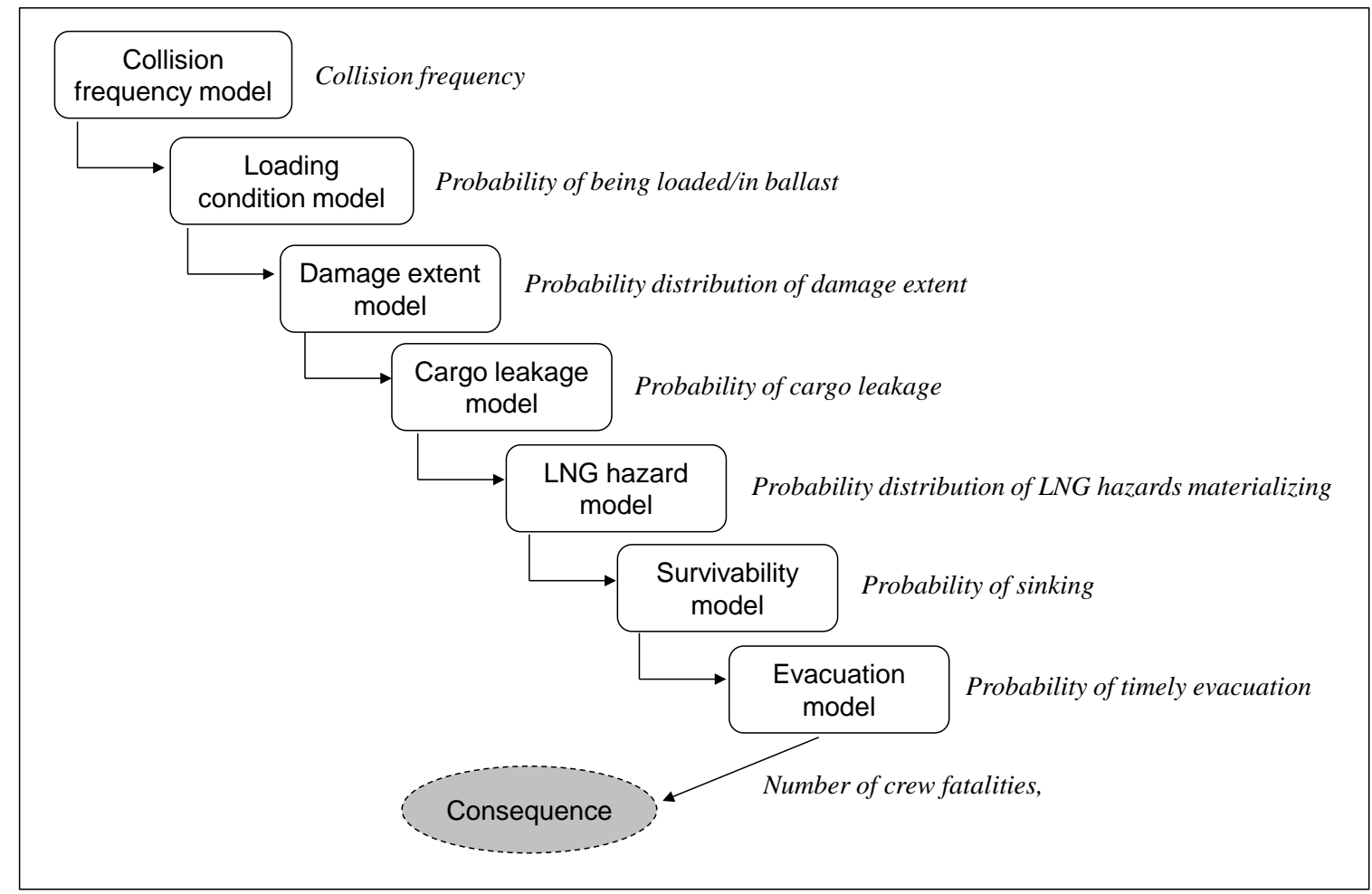

Fig. 13. High level risk model for collision scenario, LNG carrier $^{(53)}$

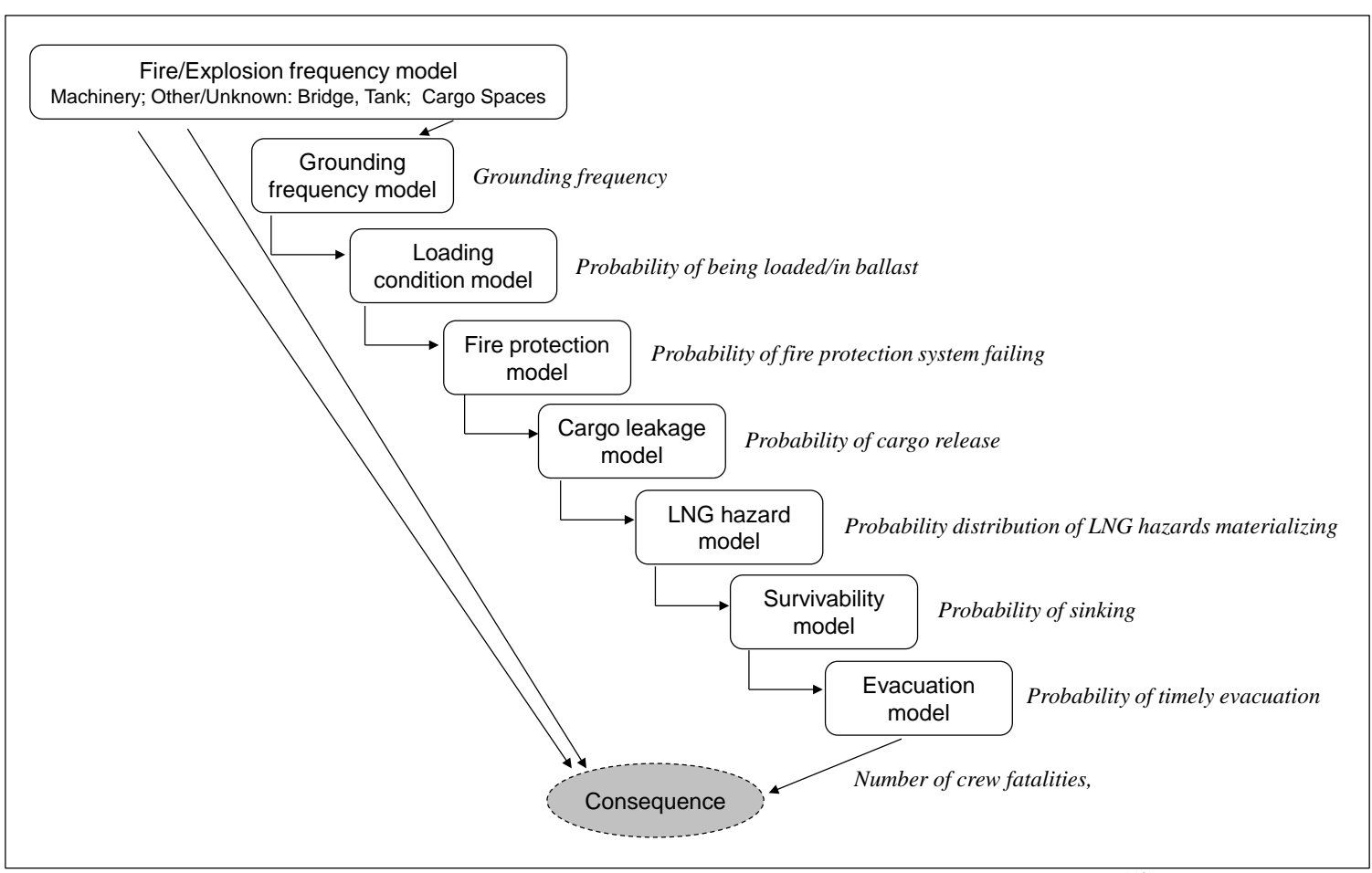

Fig. 14. High level risk model for fire and explosion scenario, LNG carrier $^{(53)}$ 


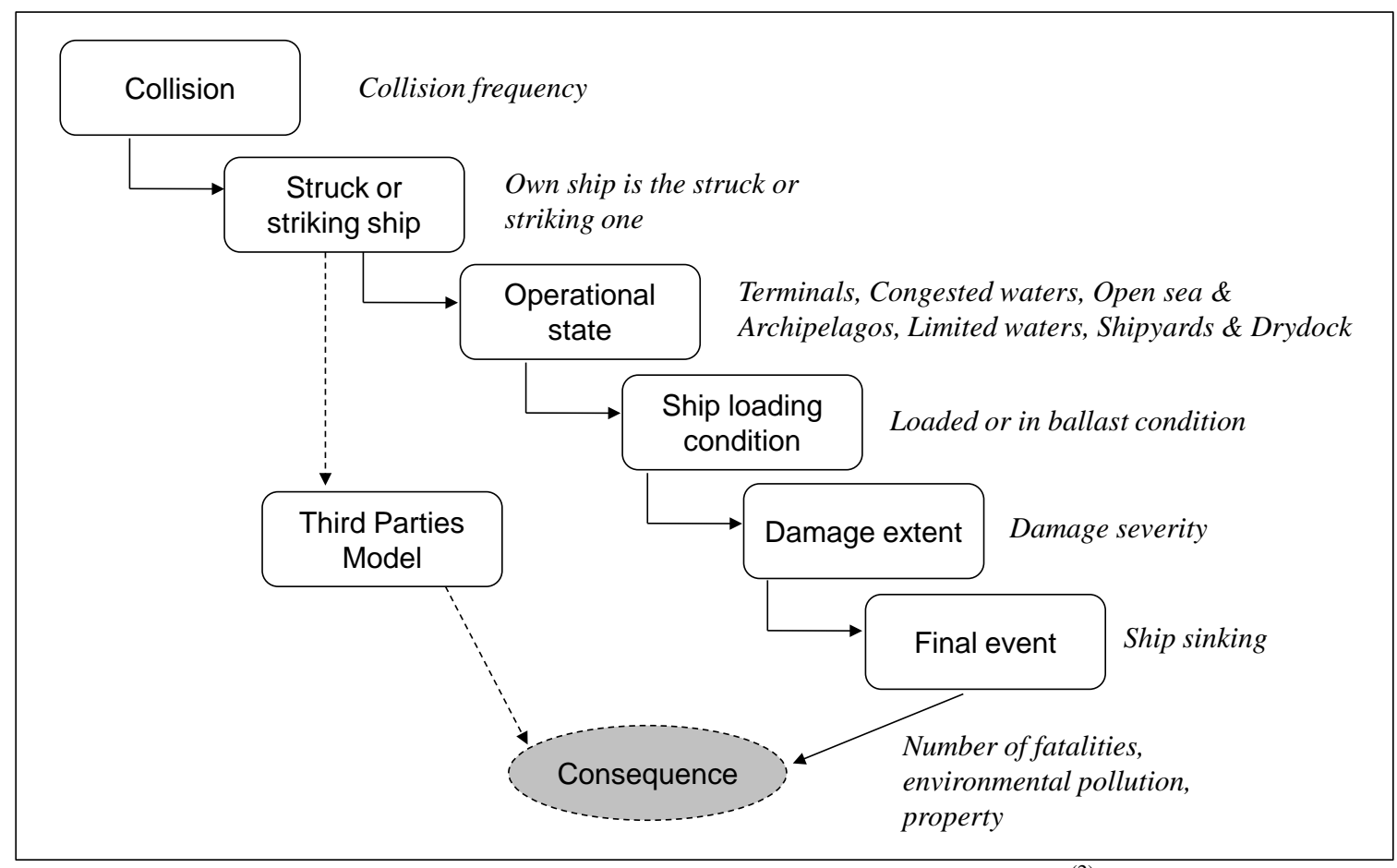

Fig. 15. High level risk model for collision scenario, oil tanker ${ }^{(2)}$

\subsection{Mechanical Model and Simulation for Consequences Estimation}

For particular scenarios in an event tree, mechanical models and simulation methods have been developed to estimate the damages to ships. The damage to the ship body after an accident occurring can be estimated by these models.

Minorsky (1959) ${ }^{(54)}$ proposed a method to calculate the kinetic energy when two ships collide based on the assumptions as follows:

1. The collision is totally inelastic;

2. The system kinetic energy along the struck ship's longitudinal direction is negligible;

3. The rotations of the struck and striking ships are small and can be neglected.

Based on the conservation of momentum, the final velocities of both ships can be calculated as,

$$
v=\frac{M_{B} v_{B}}{M_{A}+M_{B}+d m_{A}},
$$


where $M_{A}$ is the mass of struck ship; $M_{B}$ is the mass of striking ship; $d m_{A}$ is added mass of struck ship in the sway direction ( $d m_{A}=0.4 M_{A}$ is assumed); $v$ is the final velocity in the vertical direction (towards the struck ship's centerline); $v_{B}$ is the initial velocity of the striking ship in the vertical direction. The total kinetic energy absorbed in the collision is

$$
\Delta K E=\frac{1}{2} M_{B} v_{B}^{2}-\frac{1}{2}\left(M_{A}+M_{B}+d m_{A}\right) v^{2} .
$$

Based on an investigation of 26 ship-ship collisions, the volume of damaged structural steel to the energy absorbed during the collision can be derived.

Servis and Samuelides (1999) ${ }^{(55)}$ analyzed the damage to the struck ship by using finite element technique. Their method can be used to assess the collision behavior of a ship under specific collision scenario and compare the survivability of different structure arrangement.

Pedersen and Zhang (1999) ${ }^{(28)}$ proposed an analytical model to quantify the ship damage when the characteristics of both striking and struck ships are known. External dynamics and internal dynamics are considered. The method is applied to a specific RoRo passenger ship.

Chen (2000) ${ }^{(56)}$ developed a simplified collision model (SIMCOL) based on a time domain simultaneous solution of external dynamics and internal deformation mechanics. It is further computerized a software and has been used in tankers design study ${ }^{(57)}$. The SIMCOL model is also described in Brown and Chen (2002) ${ }^{(58)}$ and Brown (2002) ${ }^{(59)}$.

van de Wiel and van Dorp (2009) ${ }^{(60)}$ developed an oil outflow model for collision and grounding accidents of tankers. Various factors such as tanker hull design (single or double), struck ship displacement and speed, striking ship displacement and speed, 
and the interaction angle are considered in the model. The longitudinal and transversal damage extents of the tanker can then be calculated. Based on the damage information, the volume of oil outflow can be estimated.

Some relevant studies focus on the energy calculation ${ }^{(61-67)}$, some models analyze the impact to ship structure ${ }^{(68-79)}$, and other models evaluate the ships performance and oil spill scales following the accidents ${ }^{\left({ }^{(0-85)}\right.}$. Recently, Pedersen ${ }^{(6)}$ presented a review paper on the ship collision and grounding analysis tools. Pedersen's paper introduces one type of mathematical model (the Pedersen model) for the estimation of collision probability and some mechanical methods for estimating the ship damage.

\section{DISCUSSIONS AND RECOMMENDATIONS}

Although the framework of maritime risk assessment has been well developed, two issues are still of concern. One major concern is how to quantify the effect of human errors. Statistics show that about $80 \%$ of collisions occur due to human errors (86) and it is the primary cause for most transportation accidents ${ }^{(40)}$. IMO suggested guidance on Human Reliability Analysis (HRA) ${ }^{(1)}$, some generic tools, such as Technique for Human Error Rate Prediction (THERP) and Human Error Assessment and Reduction Technique (HEART) were proposed to be adopted in maritime accident HRA. However, very few research works have been published following the IMO’s HRA guidance. Modeling human error is still challenging in a maritime risk assessment project, and future research is highly desired. It is also of great necessity for maritime authorities to collect near miss and human error data similar to those collected in the aviation domain.

The other issue is how to address the parameter uncertainties. Based on the abovementioned approaches, the risk assessment is determined by a variety of input 
parameters such as hydrographical condition, ship flow characteristics, navigational situation, etc. It is universally acknowledged that uncertainty is an unavoidable component in the risk assessment procedure. In addition, lack of data would cause difficulties for risk assessment with parameter uncertainty. The uncertainty propagation issue in maritime transportation systems has been addressed by GWURPI-VCU team ${ }^{(17,43,87)}$. The Bayesian simulation technique is applied to propagate uncertainty throughout the analysis and the case study shows that the results would be robust to the inherent uncertainties, which has been applied to risk assessment for the Washington State Ferries and ferry service expansions in San Francisco Bay by the group. It is of great significance to conduct studies incorporating the proposed technique with other risk assessment models.

\section{CONCLUDING REMARKS}

In this study, we reviewed the QRA models for shipping waterways in the literature, comprising frequency analysis and consequence analysis. The frequency estimation models are illustrated and commented in Section 2. Event tree analysis, mechanical model, and simulation models for consequence analysis are presented in Section 3. Based on our review, two issues are proposed for further studies: parameter uncertainty and quantification of human factors. The possible solutions are also proposed in the discussions and recommendations. 


\section{References}

1. IMO, Guidelines for Formal Safety Assessment (FSA) for use in the IMO rule-making process. 2002, International Maritime Organization: London.

2. IMO, Formal Safety Assessment FSA-Crude Oil Tankers. 2008, International Maritime Organization.

3. Macduff, T., Probability of Vessel Collisions. Ocean Industry, 1974. 9(9): p. 144-148.

4. Fujii, Y., H. Yamanouchi, and N. Mizuki, Some factors affecting the frequency of accidents in marine traffic. II: The probability of stranding, III: The effect of darkness on the probability of stranding. Journal of Navigation, 1974. 27: p. 239-252.

5. Wang G, Spencer J, Chen Y. Assessment of a ship's performance in accidents. Marine Structures, 2002; 15(4-5):313-333.

6. Pedersen PT. Review and application of ship collision and grounding analysis procedures. Marine Structures, 2010; Article in Press, DOI: 10.1016/j.marstruc.2010.05.001.

7. Montewka J, Hinz T, Kujala P, Matusiak J. Probability modelling of vessel collisions. Reliability Engineering and System Safety, 2010; 95(5):573-589.

8. Kujala P, Hanninen M, Arola T, Ylitalo J. Analysis of the marine traffic safety in the Gulf of Finland. Reliability Engineering and System Safety, 2009; 94(8): 1349-1357.

9. Kaneko F. Methods for probabilistic safety assessments of ships. Journal of Marine Science and Technology, 2002; 7(1):1-16.

10. Pedersen PT. Collision and grounding mechanics. Proceedings of WEGEMT'95, 1995; 125-157. 
11. Otto S, Pedersen PT, Samuelides M, Sames PC. Elements of risk analysis for collision and grounding of a RoRo passenger ferry. Marine Structures, 2002; 15(4-5):461-474.

12. Fowler TG, Sørgard E. Modeling ship transportation risk. Risk Analysis, 2000; 20(2):225-244.

13. Friis-Hansen P, Pedersen PT. Risk Analysis of Conventional and Solo Watch Keeping. Submitted to International Maritime Organisation (IMO) Maritime Safety Committee by Denmark at the 69th Session., 1998.

14. Friis-Hansen P. Simonsen BC. GRACAT: Software for grounding and collision risk analysis. Marine Structures, 2002; 15(4-5): 383-401.

15. Trucco P. Cagno E. Ruggeri F. Grande O. A Bayesian Belief Network modelling of organisational factors in risk analysis: A case study in maritime transportation. Reliability Engineering \& System Safety, 2008; 93(6): 845-856.

16. Szwed P. van Dorp JR. Merrick JRW. Mazzuchi TA. Singh A. A Bayesian paired comparison approach for relative accident probability assessment with covariate information. European Journal of Operational Research, 2006; 169(1): 157-177.

17. Merrick JRW, van Dorp JR. Speaking the truth in maritime risk assessment. Risk Analysis, 2006; 26(1):223-237.

18. Fujii Y, Tanaka K. Traffic capacity. Journal of Navigation, 1971; 24(4):543552.

19. Goodwin EM. A statistical study of ship domains. Journal of Navigation, 1975; 28(3):328-344.

20. Coldwell TG. Marine traffic behaviour in restricted waters. Journal of Navigation, 1982; 36:431-444. 
21. Davis PV, Dove MJ, Stockel CJ. A computer simulation of multi-ship encounters. Journal of Navigation, 1982; 35(2):347-352.

22. Zhao J, Wu Z, Wang F. Comments on ship domains. Journal of Navigation, 1993; 46(3): 422-436.

23. Szlapczynski R. A unified measure of collision risk derived from the concept of a ship domain. Journal of Navigation, 2006; 59(3):477-490.

24. Pietrzykowski Z. Uriasz J. The ship domain - a criterion of navigational safety assessment in an open sea area. Journal of Navigation, 2009; 62(1): 93-108.

25. Pietrzykowski Z. Ship's fuzzy domain - a criterion for navigational safety in narrow fairways. Journal of Navigation, 2008; 61(3): 499-514.

26. Wang N. An intelligent spatial collision risk based on the quaternion ship domain. Journal of Navigation, 2010; 63(4):733-749.

27. Curtis RG. Ship collision model for overtaking. Journal of the Operational Research Society, 1986; 37(4):397-406.

28. Pedersen PT, Zhang S. Collision analysis for MS Dextra. SAFER EURORO Spring Meeting, 1999; 1-33.

29. Rambøll. Navigational safety in the Sound between Denmark and Sweden (Øresund), risk and cost-benefit analysis. Virum, Denmark: The Royal Danish Administration of Navigation and Hydrography, The Danish Maritime Authority and The Swedish Maritime Administration, Rambøll Danmark A/S, Ref, 568125, R568125-002(1), August 24, 2006.

30. COWI. Risk analysis of sea traffic in the area around Bornholm. Kongens Lyngby, Denmark: COWI A/S, Report No.: P-65775-002, January 25, 2008. 
31. Tan B, Otay EN. Modeling and analysis of vessel casualties resulting from tanker traffic through narrow waterways. Naval Research Logistics, 1999; 46(8): 871-892.

32. Roeleven D, Kok M, Stipdonk HL, De Vries WA. Inland waterway transport: modelling the probability of accidents. Safety Science, 1995; 19(2-3):191-202.

33. Geng B, Wang H, Wang J. Probabilistic model for vessel-bridge collisions in the Three Gorges Reservoir. Frontiers of Architecture and Civil Engineering in China, 2009; 3(3):279-285.

34. Debnath AK, Chin HC. Hierarchical modeling of perceived collision risks in port fairways. Transportation Research Record, 2009; 2100:68-75.

35. Chin HC, Debnath AK. Modeling perceived collision risk in port water navigation. Safety Science, 2009; 47(10):1410-1416.

36. GWU-RPI-VCU. The Washington State ferries risk assessment. The George Washington University, Rensselaer Polytechnic Institute, Virginia Commonwealth University, July 1, 1999.

37. van Dorp JR, Merrick JRW, Harrald JR, Mazzuchi TA, Grabowski M. A risk management procedure for the Washington state ferries. Risk Analysis, 2001; 21(1):127-142.

38. Merrick JRW, van Dorp JR, Mazzuchi TA, Harrald JR, Spahn JE, Grabowski M. The Prince William sound risk assessment. Interfaces, 2002; 32(6):25-40.

39. Merrick JRW, van Dorp JR, Blackford JP, Shaw GL, Harrald JR, Mazzuchi TA. A traffic density analysis of proposed ferry service expansion in San Francisco bay using a maritime simulation model. Reliability Engineering and System Safety, 2003; 81(2):119-132. 
40. Harrald JR, Mazzuchi TA, Spahn JE, van Dorp JR, Merrick JRW, Shrestha S, Grabowski M. Using system simulation to model the impact of human error in a maritime system. Safety Science, 1998; 30(1-2):235-247.

41. Merrick JRW, van Dorp JR, Harrald JR, Mazzuchi TA, Spahn JE, Grabowski M. A systems approach to managing oil transportation risk in prince william sound. Systems Engineering, 2000; 3(3):128-142.

42. Merrick JRW, van Dorp JR, Mazzuchi TA, Harrald JR. Modeling risk in the dynamic environment of maritime transportation. Winter Simulation Conference Proceedings, 2001; 2:1090-1098.

43. Merrick JRW, van Dorp JR, Dinesh V. Assessing uncertainty in simulationbased maritime risk assessment. Risk Analysis, 2005; 25(3):731-743.

44. van Dorp JR, Merrick JRW. On a risk management analysis of oil spill risk using maritime transportation system simulation. Annals of Operations Research, 2009; Article in Press, DOI: 10.1007/s10479-009-0678-1.

45. Ulusçu ÖS, Özbaş B, Altiok T, Or I. Risk analysis of the vessel traffic in the strait of Istanbul. Risk Analysis, 2009; 29(10):1454-1472.

46. Hong Kong Marine Department. Marine traffic risk assessment for Hong Kong waters (MARA Study). Hong Kong: Hong Kong Marine Department, Report Ref: R8152/20 Issue 1, March, 2004.

47. Qu X, Meng Q. Development and applications of a simulation model for vessels in the Singapore Straits. Expert Systems with Applications, 39(9), 8430-8438.

48. IMO. Formal safety assessment FSA- container vessels. London: International Maritime Organization, Document No.: MSC83/INF.8, July 3, 2007. 
49. IMO. Formal safety assessment FSA- liquefied natural gas(LNG) carriers. London: International Maritime Organization, Document No.: MSC83/INF.3, July 3, 2007.

50. IMO. Formal safety assessment FSA- cruise ships. London: International Maritime Organization, Document No.: MSC85/INF.2, July 21, 2008.

51. IMO. Formal safety assessment FSA- RoPax ships. London: International Maritime Organization, Document No.: MSC85/INF.3, July 21, 2008.

52. Ronza A, Félez S, Darbra RM, Carol S, Vílchez JA, Casal J. Predicting the frequency of accidents in port areas by developing event trees from historical analysis. Journal of Loss Prevention in the Process Industries, 2003; 16(6):551-560.

53. Vanem E, Antão P, FDC de Comas, Skjong R. Formal safety assessment of LNG tankers. 10th Inter-national Symposium on Practical Design of Ships and Other Floating Structures, PRADS 2007.

54. Minorsky VU. An analysis of ship collisions with reference to protection of nuclear power plants. Journal of Ship Research, 1959; 3(2):1-4.

55. Servis DP, Samuelides M. Ship collision analysis using finite elements. SAFER EURORO Spring Meeting, 1999.

56. Chen D. Simplified ship collision model [Master Thesis]. [Blacksburg, Virginia]: Virginia Polytechnic Institute and State University; January 2000.

57. Transportation Research Board. Environmental performance of tanker designs in collision and grounding, methods for comparison. Washington, D. C.: Marine Board, Transportation Research Board, The National Academies, National Academy Press, Special report 259, 2001. 
58. Brown A, Chen D. Probabilistic method for predicting ship collision damage. Ocean Engineering International Journal, 2002; 6(1):54-65.

59. Brown A. Collision scenarios and probabilistic collision damage. Marine Structures, 2002; 15(4-5):335-364.

60. Van de Wiel G, Van Dorp JR. An oil outflow model for tanker collisions and groundings. Annals of Operations Research, 2009; Article in Press, DOI: 10.1007/s10479-009-0674-5.

61. Pedersen PT, Zhang S. On impact mechanics in ship collisions. Marine Structures, 1998; 11(10):429-449.

62. Pedersen PT, Zhang S. Absorbed energy in ship collisions and groundingrevising Minorsky's empirical method. Journal of Ship Research, 2000; 44(2):140-154.

63. Glykas A, Das PK. Energy conservation during grounding with rigid slopes. Ocean Engineering, 2001; 28(4):397-415.

64. Glykas A, Das PK. Energy conservation during a tanker collision. Ocean Engineering, 2001; 28(4):361-374.

65. Glykas A, Das PK, Barltrop N. Application of failure and fracture criteria during a tanker head-on collision. Ocean Engineering, 2001; 28(4):375-395.

66. Lehmann E, Peschmann J. Energy absorption by the steel structure of ships in the event of collisions. Marine Structures, 2002; 15(4-5):429-441.

67. Tabri K, Broekhuijsen J, Matusiak J, Varsta P. Analytical modelling of ship collision based on full-scale experiments. Marine Structures, 2009; 22(1):4261.

68. Asadi GV, Vaughan H. Dynamics and structural damage of tanker ships running aground. Journal of Hazardous Materials, 1990; 25(1-2):61-73. 
69. Ohtsubo H, Kawamoto Y, Kuroiwa T. Experimental and numerical research on ship collision and grounding of oil tankers. Nuclear Engineering and Design, 1994; 150(2-3):385-396.

70. Paik JK, Pedersen PT. Modelling of the internal mechanics in ship collisions. Ocean Engineering, 1996; 23(2):107-142.

71. Simonsen BC, Wierzbicki T. Grounding bottom damage and ship motion over a rock. International Journal of Offshore and Polar Engineering, 1996; 6(3):195-202.

72. Simonsen BC. Ship grounding on rock - I. Theory. Marine Structures, 1997; 10(7):519-562.

73. Simonsen BC. Ship grounding on rock - II. Validation and application. Marine Structures, 1997; 10(7):563-584.

74. Pedersen PT, Zhang S. Effect of ship structure and size on grounding and collision damage distributions. Ocean Engineering, 2000; 27(11):1161-1179.

75. Kitamura O. FEM approach to the simulation of collision and grounding damage. Marine Structures, 2002; 15(4-5):403-428.

76. Wang G, Chen Y, Zhang H, Peng H. Longitudinal strength of ships with accidental damages. Marine Structures, 2002; 15(2):119-138.

77. Ozguc O, Das PK, Barltrop N. A comparative study on the structural integrity of single and double side skin bulk carriers under collision damage. Marine Structures, 2005; 18(7-8):511-547.

78. Ehlers S, Broekhuijsen J, Alsos HS, Biehl F, Tabri K. Simulating the collision response of ship side structures: A failure criteria benchmark study. International Shipbuilding Progress, 2008; 55(1-2):127-144. 
79. Luís RM, Teixeira AP, Guedes Soares C. Longitudinal strength reliability of a tanker hull accidentally grounded. Structural Safety, 2009; 31(3):224-233.

80. Cuesta I, Grau FX, Giralt F. Numerical simulation of oil spills in a generalized domain. Oil and Chemical Pollution, 1990; 7(2):143-159.

81. Sirkar J, Ameer P, Brown AJ, Goss P, Michel K, Nicastro F, Willis W. A Framework for Assessing the Environmental Performance of Tankers in Accidental Grounding and Collision. SNAME Transactions, 1997; 105:253295.

82. Rawson C, Crake K, Brown AJ. Assessing the Environmental Performance of Tankers in Accidental Grounding and Collision. SNAME Transactions, 1998; 106:41-58.

83. Skjong R, Vanem E. Damage stability evaluation in collision of bulk carriers. 3rd International Conference on Collision and Grounding of Ships (ICCGS2004), 2004.

84. Vanem E, Skjong R. Collision and grounding of passenger ships - risk assessment and emergency evacuations. 3rd International Conference on Collision and Grounding of Ships (ICCGS2004), 2004.

85. Fang C, Das PK. Survivability and reliability of damaged ships after collision and grounding. Ocean Engineering, 2005; 32(3-4):293-307.

86. Macrae C. Human factors at sea: Common patterns of error in groundings and collisions. Maritime Policy and Management, 2009; 36(1):21-38.

87. Merrick JRW, van Dorp JR. Singh A. Analysis of correlated expert judgments from extended pairwise comparisons. Decision Analysis, 2005; 2(1): 17-29. 
88. Qu X., and Meng Q., 2012. The economic importance of the Straits of Malacca and Singapore: An extreme-scenario analysis. Transportation Research Part E, 48(1): 258-265.

89. Qu X., Q Meng, L Suyi, 2011. Ship collision risk assessment for the Singapore Strait. Accident Analysis and Prevention. 43(6): 2030-2036. 